EMANOEL GLEDESTON DANTAS LICARIÃO

\title{
Efeito do treinamento físico em portadores de marcapasso definitivo
}

Tese apresentada à Faculdade de Medicina da Universidade de São Paulo para obtenção do título de Doutor em Ciências

Programa de Cardiologia

Orientador: Prof. Dr. Martino Martinelli Filho

São Paulo

2016 


\section{Dados Internacionais de Catalogação na Publicação (CIP)}

Preparada pela Biblioteca da

Faculdade de Medicina da Universidade de São Paulo

Creprodução autorizada pelo autor

Licarião, Emanoel Gledeston Dantas

Efeito do treinamento físico em portadores de marcapasso definitivo / Emanoel

Gledeston Dantas Licarião. -- São Paulo, 2016.

Tese(doutorado)--Faculdade de Medicina da Universidade de São Paulo.

Programa de Cardiologia.

Orientador: Martino Martinelli Filho.

Descritores: 1.Exercício 2.Marcapasso 3.Qualidade de vida 4.Consumo de oxigênio 5.Estilo de vida sedentário 6.Arritmias cardíacas

USP/FM/DBD-268/16 


\section{Dedicatória}

In memoriam

A minha irmã Sayonara e minha mãe Valmira Licarião, incentivadoras e admiradoras de minha carreira profissional. Ambas sempre me inspiraram a seguir em frente independente das adversidades. Hoje, estão nos braços de nosso Deus criador, onde um dia nos encontraremos. 


\section{Agradecimentos}

A Deus, por todas as bênçãos recebidas em minha vida.

A minha esposa Verônica, que pacientemente me apoiou e compreendeu minhas ausências .

A meus filhos, Renoir, Victor, Isabelle e Sophie, e minha neta, Beatriz, maiores estímulos às minhas lutas.

A meu pai Renan, incentivador e amigo.

Ao meu eterno mestre e amigo Silas Galvão, por haver me iniciado na Estimulação Cardíaca Artificial.

Aos amigos Zolmo, Janete Jenel, Sérgio Siqueira, Gisele Lopes e Denise Lobo pelo apoio à viabilização desta pesquisa.

Ao meu estimado orientador e incentivador Prof. Dr. Martino Martinelli, a quem tributo grande parte deste sucesso. 


\section{NORMATIZAÇÃO}

Esta tese está de acordo com as seguintes normas, em vigor no momento desta publicação:

Referências: adaptado de International Committee of Medical Journals Editors (Vancouver).

Universidade de São Paulo. Faculdade de Medicina. Serviço de Biblioteca e Documentação. Guia de apresentação de dissertação, teses e monografias. Elaborado por Anneliese Carneiro da Cunha, Maria Júlia de A. L. Freddi, Maria F. Crestana, Marinalva de Souza Aragão, Suely Campos Cardoso, Valéria Vilhena. $3^{\mathrm{a}}$ ed. São Paulo: Divisão de Biblioteca e Documentação; 2011.

Abreviaturas dos títulos dos periódicos, de acordo com List of Journals Indexed in Index Medicus. 


\section{Sumário}

Lista de abreviaturas

Lista de figuras

Lista de tabelas

Resumo

Abstract

1 INTRODUÇÃO

1.1 Marcapasso cardíaco definitivo.................................................................................. 2

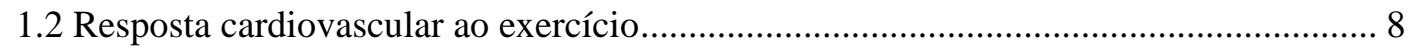

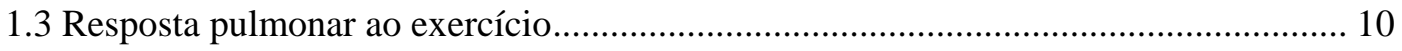

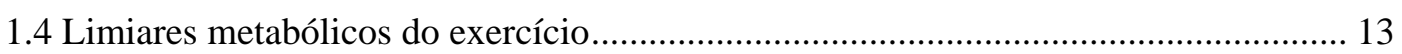

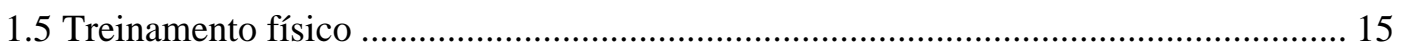

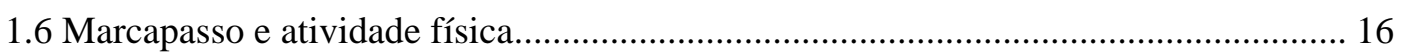

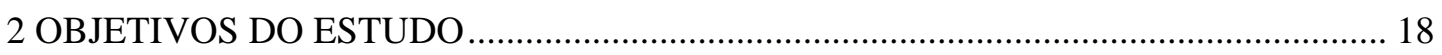

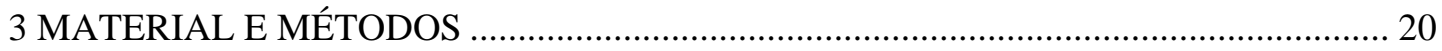

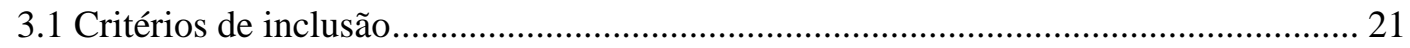

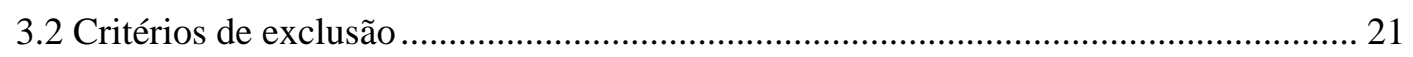

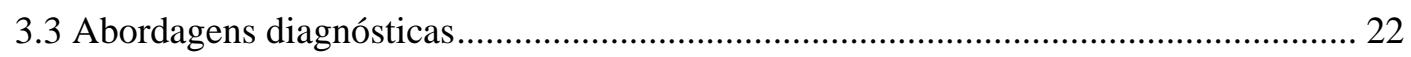

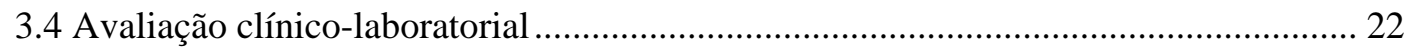

3.5 Questionários de qualidade de vida - SF-36 e Aquarel ................................................. 22

3.6 Avaliação cardiopulmonar em esforço............................................................................. 23

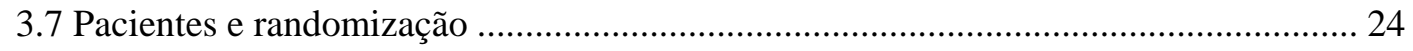

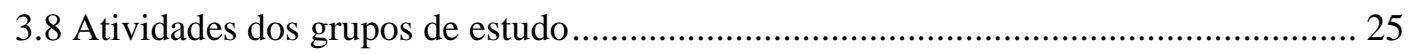

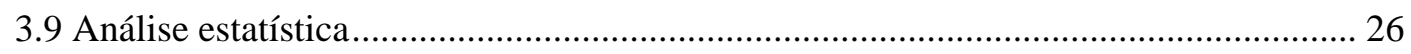

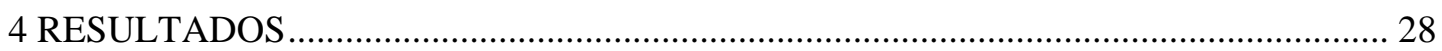

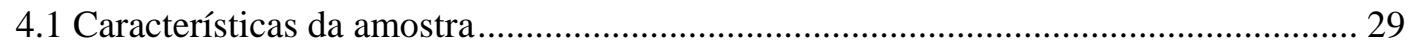

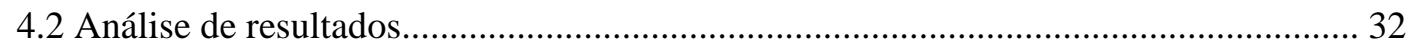

4.2.1 Avaliação de homogeneidade entre os grupos .................................................. 32

4.2.2 Parâmetros de avaliação cardiopulmonar em esforço ........................................ 34

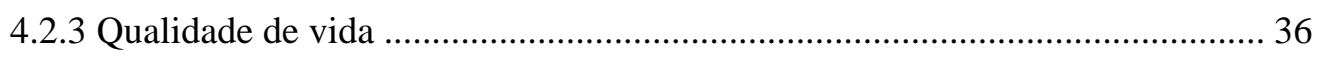

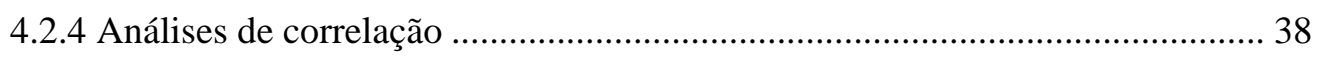


5 DISCUSSÃO

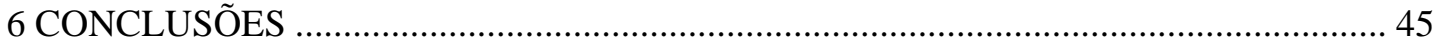

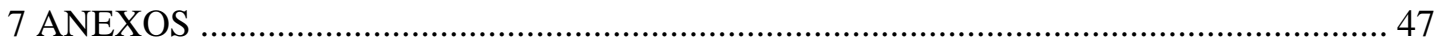

Anexo A - Termo de Consentimento Livre e Esclarecido.................................................. 48

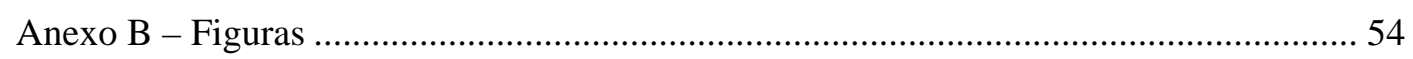

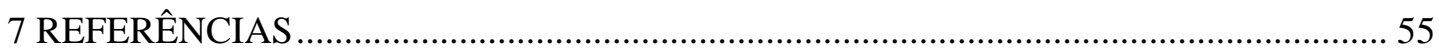




\section{LISTA DE ABREVIATURAS}

ACE

AV

BAV de $2^{\circ}$ Grau Bloqueio atrioventricular de segundo grau

BAV

BAVT

BTPS

CFIC

CFM

DP

ECG

FC

FEVE

GC

GTFNS

GTFS

Holter de 24h

ICC

LA

MCD

mhp

PCR

$\mathrm{PETCO}_{2}$

$\mathrm{PETO}_{2}$
Avaliação Cardiopulmonar ao Esforço

Átrio ventricular

Bloqueio atrioventricular

Bloqueio atrioventricular total

Body temperature pressure satured

Classificação funcional da insuficiência cardíaca

Capacidade funcional máxima

Desvio padrão

Eletrocardiograma

Frequência cardíaca

Fração de ejeção de ventrículo esquerdo

Grupo controle

Grupo de treinamento físico não supervisionado

Grupo de treinamento físico supervisionado

Monitoramento eletrocardiográfico ambulatorial dinâmico por $24 \mathrm{~h}$

Insuficiência cardíaca congestiva

Limiar anaeróbico

Marcapasso cardíaco definitivo

Milha por hora

Ponto de compensação respiratória eu limiar anaeróbico \#

Pressão expiratória final de $\mathrm{CO}_{2}$

Pressão expiratória final de $\mathrm{O}_{2}$ 
PVARP

QdV

$\mathrm{RER} / \mathrm{RQ}$

STPD

TEE

$\mathrm{VE} / \mathrm{VCO}_{2}$

$\mathrm{VE} / \mathrm{VO}_{2}$

$\mathrm{VO}_{2 \text { máx }}$

$\mathrm{VO}_{\text {2pico }}$
Período refratário atrial pós-evento ventricular

Qualidade de vida

Razão de troca respiratória

Standard temperature pressured and dry

Teste ergoespirométrico

Equivalente ventilatório de $\mathrm{CO}_{2}$

Equivalente ventilatório de $\mathrm{O}_{2}$

Consumo máximo de oxigênio

Consumo de oxigênio de pico 


\section{LISTA DE FIGURAS}

Figura 1 - A: marcapasso dupla câmara, composto por gerador e caboseletrodos no átrio e ventrículo; B: Marcapasso de câmara única com cabo-eletrodo no ventrículo

Figura 2 - Acesso endovenoso para implante do cabo-eletrodo e fixação subcutânea do gerador

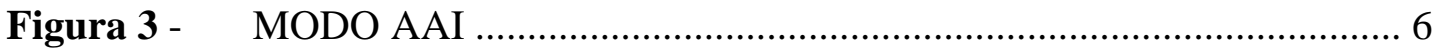

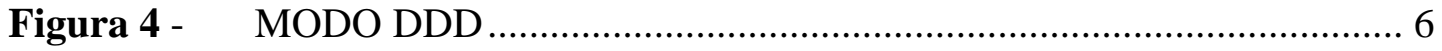

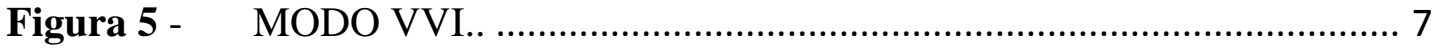

Figura 6 - Diagrama representativo do processo respiratório. Nele estão descritos os processos respiratórios externos e internos

Figura 7 - Gráfico representativo dos volumes pulmonares

Figura 8 - Esquema representativo dos níveis de intensidade do exercício em relação ao $\mathrm{VO}_{2}$, em função da carga de trabalho

Figura 9 - Fluxograma do estudo incluindo a casuística por grupo, conforme randomização

Figura 10 - Análise comparativa entre os momentos Pré x Pós da Carga e $\mathrm{Vo}_{\text {2máx }}$ do TEE nos três grupos 


\section{LISTA DE TABELAS}

Tabela 1 - Características funcionais e operacionais do MCD ........................... 5

Tabela 2 - Características clínico-funcionais basais da casuística..................... 31

Tabela 3 - Análise comparativa das características clínico-funcionais basais entre os grupos .............................................................. 33

Tabela 4 - Análise comparativa entre os momentos Pré x Pós da Carga e $\mathrm{Vo}_{2 \text { máx }}$ do TEE ...................................................................................... 34

Tabela 5 - $\quad$ Análise comparativa entre os momentos Pré x Pós do Pulso $\mathrm{O}_{2}$

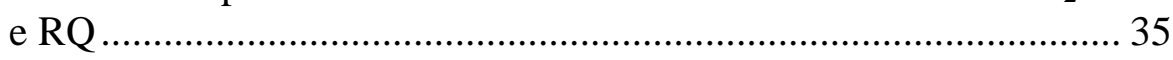

Tabela 6 - Análise comparativa entre os momentos Pré x Pós da FCmax e \% da FC Predita ................................................................................... 36

Tabela 7 - $\quad$ Análise comparativa da QdV Pré x Pós, em cada grupo ................... 37

Tabela 8 - $\quad$ Análise da correlação entre os domínios da QdV e $\mathrm{VO}_{2 \text { pico }}$............... 38 


\section{Resumo}

Licarião EGD. Efeitos do treinamento físico em portadores de marcapasso definitivo [Tese]. São Paulo: Faculdade de Medicina, Universidade de São Paulo, 2016.

Inúmeros problemas cotidianos estão mal esclarecidos para portadores de marcapasso cardíaco definitivo (MCD). Dentre eles, destaca-se sua relação com atividades físicas e programas de treinamento. Este estudo, PRACTICING - Physical Training Effect In Pacemaker Patients, tem o objetivo de avaliar o impacto do treinamento físico sobre o consumo de oxigênio $\left(\mathrm{VO}_{2}\right.$ pico) e a qualidade de vida em portadores de MCD. Métodos - estudo prospectivo, unicêntrico e randomizado que incluiu portadores de MCD atrioventricular com funções sinusal e ventricular normais, sedentários, com idade entre 18 e 80 anos. Os pacientes foram distribuídos em três grupos: GTFS - grupo treinamento físico supervisionado; GTFNS treinamento físico não supervisionado e GC - controle. Foram analisadas as variáveis obtidas por teste ergoespirométrico (TEE) e questionários de qualidade de vida (SF36 e Aquarel), no inicio do estudo e após 4 meses de seguimento. Resultados Foram incluídos 18 pacientes no GTFS; 20 no GTFNS e 20 no GC. A idade média foi 55,4 \pm 10 anos, $69,0 \%$ era do sexo feminino e a FEVE média foi $63,41 \pm 5,0 \%$. Hipertensão arterial, diabetes mellitus e doença de Chagas estiveram presentes em 56,9\%, 25,8\% e 25,9\%, respectivamente. O tempo médio de uso de MCD foi de $59,4 \pm 62,6$ meses. O $\mathrm{VO}_{2}$ máx médio inicial da população foi de $24,0 \pm 5,8 \mathrm{ml} / \mathrm{kg} / \mathrm{min}$ e não houve diferença entre os três grupos $(P=0,279)$. Apenas no GTFS ocorreu melhora significativa no $\mathrm{VO}_{2}$ máx após treinamento físico: $23,86 \pm 4,38$ versus $26,74 \pm 4,18 \mathrm{ml} / \mathrm{kg} / \mathrm{min}$, $(P=0,001)$. A avaliação da qualidade de vida demonstrou apenas diferença no domínio desconforto no peito no GTFNS e dispneia no GC (Aquarell). Conclusão - Em portadores de MCD sem disfunção ventricular, o treinamento físico supervisionado proporcionou melhora expressiva do consumo de oxigênio e de suas repercussões funcionais, embora com baixo impacto na qualidade de vida.

Descritores: 1. Exercício 2. Marcapasso 3. Qualidade de vida 4. Consumo de oxigênio 5. Estilo de vida sedentário 6. Arritmias cardíacas 


\section{Abstract}

Licarião EGD. Physical training effect in pacemaker patients [Thesis]. São Paulo: “Faculdade de Medicina, Universidade de São Paulo”, 2016.

Many everyday problems are poorly cleared for permanent cardiac pacemaker (MCD). Among these, there is its relation to physical activities and training programs. This study, PRACTICING- Physical Training Effect In Pacemaker Patients - aimed to assess the impact of physical training on the oxygen uptake $\left(\mathrm{V}_{\mathrm{O} 2}\right.$ peak) and the quality of life in patients with MCD. Methods - prospective, singlecenter, randomized trial that included patients with atrioventricular MCD with sinus function and ventricular normal, sedentary, aged between 18 and 80 years. Patients were divided into three groups: GTFS - group supervised physical training; GTFNS physical training unsupervised and GC - control. We analyzed the variables obtained by cardiopulmonary exercise test form (TEE) and quality of life questionnaires (SF36 and Aquarel) at study start and after four months of follow-up. Results - We included 18 patients in GTFS; 20 in GTFNS and 20 in the control group. The mean age was $55.4 \pm 10$ years, $69.0 \%$ were female and the mean LVEF was $63.41 \pm 5.0 \%$. hypertension, diabetes mellitus and Chagas disease were present in 56.9\%, 25.8\% and $25.9 \%$, respectively. The average time of use of MCD was $59.4 \pm 62.6$ months. The initial average $\mathrm{VO}_{2 \max }$ of the population was $24.0 \pm 5,8 \mathrm{ml} / \mathrm{kg} / \mathrm{min}$ and there was no difference among the three groups $(P=0.279)$. Only in GTFS was significant improvement in $\mathrm{VO}_{2 \max }$ after physical training: $23.86 \pm 4.38$ versus $26.74 \pm 4,18$ $\mathrm{ml} / \mathrm{kg} / \mathrm{min}(\mathrm{P}=0.001)$. The evaluation of quality of life, demonstrated only difference in discomfort in the chest area in GTFNS and dyspnoea in CG (Aquarell). Conclusion - In patients with MCD without ventricular dysfunction, physical training protocol supervised provided significant improvement in oxygen uptake and its functional repercussions, albeit with low impact on quality of life.

Descriptors: 1. Exercise 2. Pacemaker 3. Quality of life 4. Oxygen consumption 5. Sedentary lifestyle 6. Cardiac arrhythmias 
1 Introdução 


\section{INTRODUÇÃO}

Exercício físico, adequadamente praticado, proporciona benefícios à saúde da população em geral e implica em melhora da qualidade de vida e da longevidade ${ }^{1,2}$.

Muitos pacientes com doença cardiovascular praticam exercícios físicos com a finalidade de obter benefícios adicionais ao tratamento médico. Nesses casos, o treinamento físico protocolar tem demonstrado resultados convincentes, além de aumentar a segurança do paciente à realização de atividades esportivas ${ }^{1}$.

Portadores de Marcapasso Cardíaco Definitivo (MCD) frequentemente apresentam cardiopatias associadas e, com isso, sentem-se muito limitados em relação à prática de atividades físicas. Nesse sentido, tendem a se tornar cada vez mais inseguros porque não dispõem de protocolos ou programas de treinamento físico.

A seguir, vamos discorrer sobre as peculiaridades que envolvem o MCD e seus portadores, assim como sobre as evidências atuais relativas ao treinamento físico cardiovascular e possíveis aplicações aos pacientes com MCD.

\subsection{Marcapasso cardíaco definitivo}

O MCD é um tipo de dispositivo cardíaco eletrônico implantável (DCEI). O MCD é um sistema de estimulação cardíaca artificial composto por gerador de pulsos e cabo-eletrodo. Pode ser de câmara única (atrial ou ventricular) ou câmara dupla (atrial e ventricular) - Figura 1. 


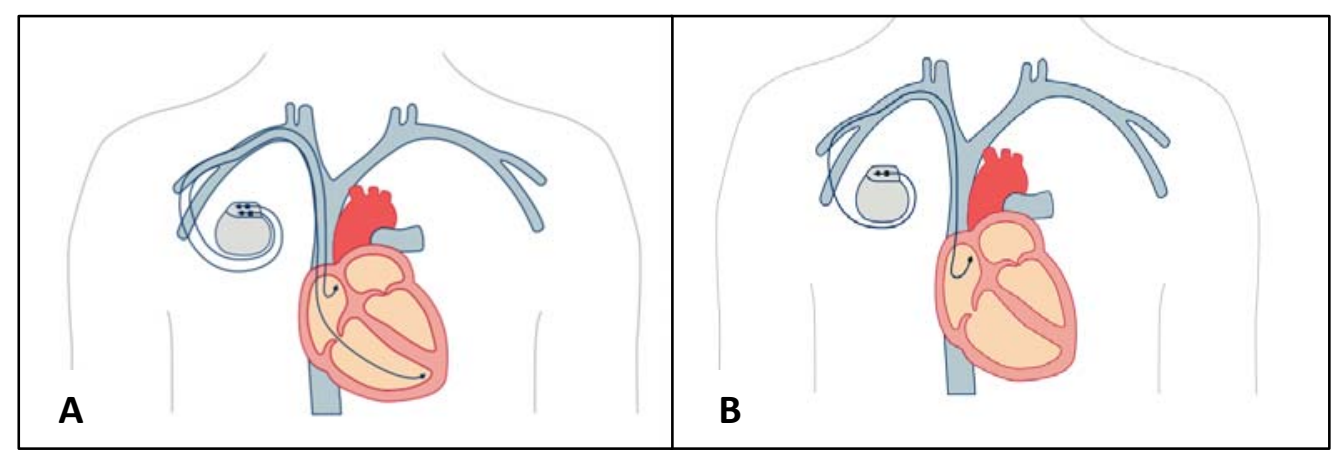

Fonte - Biotronik Guide, $2011^{3}$.

Figura 1 - A: Marcapasso dupla câmara, composto por gerador e cabos-eletrodos no átrio e ventrículo; B: Marcapasso de câmara única com caboeletrodo no ventrículo

Também são considerados DCEIs o ressincronizador cardíaco (RC), o cardioversor-desfibrilador implantável (CDI) e o ressincronizador-cardioversor desfibrilador (RC-D).

O gerador de pulsos do MCD é constituído por bateria ou fonte de energia de lítio/iodo não-recarregável e por sofisticado circuito eletrônico. Essa estrutura é capaz de gerar estímulos elétricos e acionar inúmeros algoritmos responsáveis por funções básicas e específicas, tais como o armazenamento de dados e eletrogramas intracardíacos ${ }^{4,5}$.

O cabo-eletrodo é o responsável pela condução dos estímulos elétricos desde o gerador até o músculo cardíaco e pela captação de sinais elétricos próprios do coração. Trata-se de um condutor revestido por silicone ou poliuretano dotado de inúmeros filamentos, suficientemente flexível para permitir adequada manipulação durante os processos de sua introdução, posicionamento e fixação no músculo cardíaco $^{4,5}$.

As indicações mais comuns para implante de MCD incluem as bradiarritmias: doença do nó sinoatrial e bloqueio atrioventricular.

O implante do MCD, na grande maioria das vezes, é endocavitário. A via de acesso mais praticada é a veia cefálica, podendo ser utilizada a jugular ou, raramente, a veia femoral (Figura 2). 


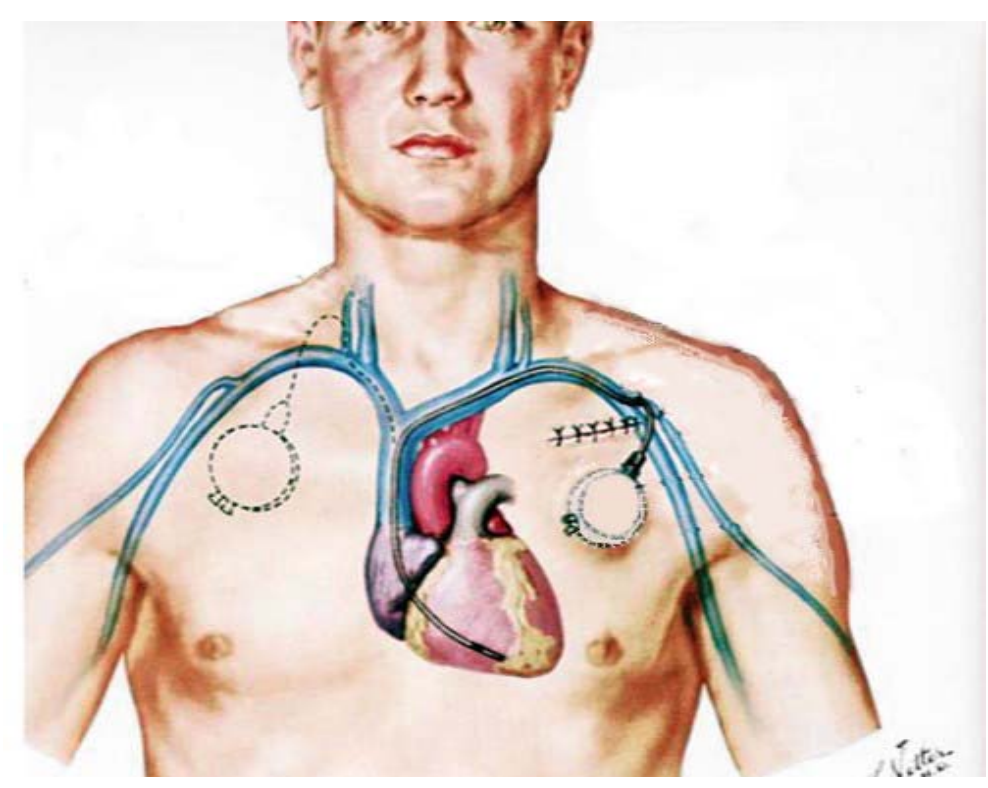

Fonte - Adaptado de Netter, $2015^{6}$

Figura 2 - Acesso endovenoso para implante do cabo-eletrodo e fixação subcutânea do gerador

As características funcionais e operacionais do MCD são definidas por um Código de 5 letras (Tabela 1):

A primeira letra define a câmara cardíaca a ser estimulada: A - Átrio; V Ventrículo; O - Nenhuma; D - Átrio e Ventrículo;

A segunda letra define a câmara cardíaca com potencial elétrico endocavitário sentido: A - Átrio; V - Ventrículo; O - Nenhuma; D - Átrio e Ventrículo;

A terceira letra corresponde à maneira pela qual o algoritmo de programação do gerador atua em função do potencial endocavitário sentido. Pode-se (I) inibir ou (T) deflagrar um estímulo elétrico simultâneo, (D) ambos ou (O) nenhum;

A quarta letra refere-se aos recursos de resposta de frequência cardíaca (R);

A quinta letra refere-se à função multissítio (A) átrio, (V) ventrículo, (D) ambos ou (O) nenhuma. 
Tabela 1 - Características funcionais e operacionais do MCD

\begin{tabular}{|c|c|c|c|c|}
\hline $1^{\text {a }}$ Letra & $2^{\text {a }}$ Letra & $3^{\text {a }}$ Letra & $4^{\text {a }}$ Letra & $5^{\mathrm{a}}$ Letra \\
\hline $\begin{array}{c}\text { Câmara cardíaca a ser } \\
\text { estimulada }\end{array}$ & $\begin{array}{l}\text { Câmara com } \\
\text { potencial } \\
\text { endocavitário } \\
\text { sentido }\end{array}$ & $\begin{array}{l}\text { Programação do gerador } \\
\text { em função do potencial } \\
\text { endocavitário sentido }\end{array}$ & $\begin{array}{l}\text { Reposta de } \\
\text { frequência }\end{array}$ & Função multisítio \\
\hline A- Átrio & A & I - Inibir & R- Com resposta & A \\
\hline V- Ventrículo & $\mathrm{V}$ & T- Deflagrar estímulo & O- Sem resposta & V \\
\hline Duplo- Duplo (A e V) & $\mathrm{D}$ & D - Ambos & & $\mathrm{D}(\mathrm{A}+\mathrm{V})$ \\
\hline O- (nenhuma) & $\mathrm{O}$ & O- Nenhum & & $\mathrm{O}$ \\
\hline
\end{tabular}

Fonte: Revisado do NASPE (North American Society of Pacing and Electrophysiology) e BPEG (British Pacing and Electrophysiology Group). Ellenbogen KA, Kaszala K. Cardiac Pacing and ICDs. 6a. ed. ${ }^{5}$

A programação dos inúmeros algoritmos funcionais contidos no MCD é realizada por meio de dispositivos computadorizados dedicados (programadores).

Assim, de acordo com a indicação e situação clínica do paciente, o MCD pode ser programado nos seguintes modos:

AAI: Estimula e sente o átrio e se inibe na presença de potencial endocavitário atrial (Figura 3).

VVI: Estimula e sente a câmara ventricular e se inibe na presença de potencial endocavitário ventricular (Figura 4).

DDD: Estimula a câmara atrial e ventricular mantendo sincronismo AV, sente as duas câmaras e inibe ou deflagra de acordo com os intervalos programáveis (Figura 5).

Esses modos podem contar com o acionamento da função sensor de resposta de frequência. Com isso, acrescenta-se a letra R. No caso de função multissítio acresce-se a quinta-letra. 


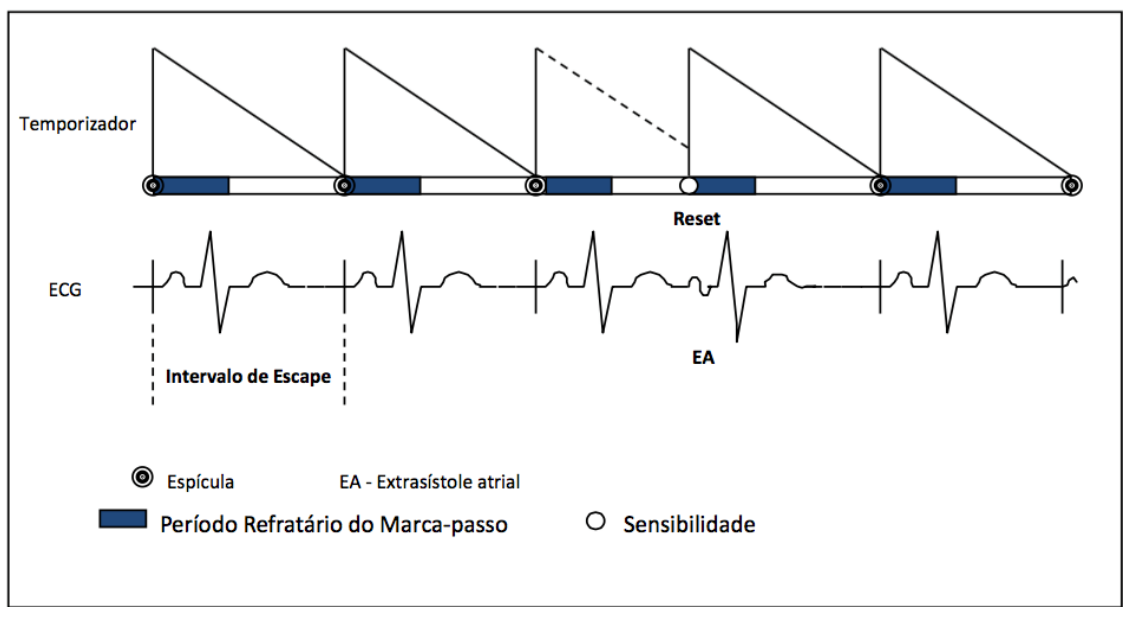

Fonte: Atlas de Marcapasso. Martinelli et al. ${ }^{7}$

Figura 3 - Diagrama do MODO AAI

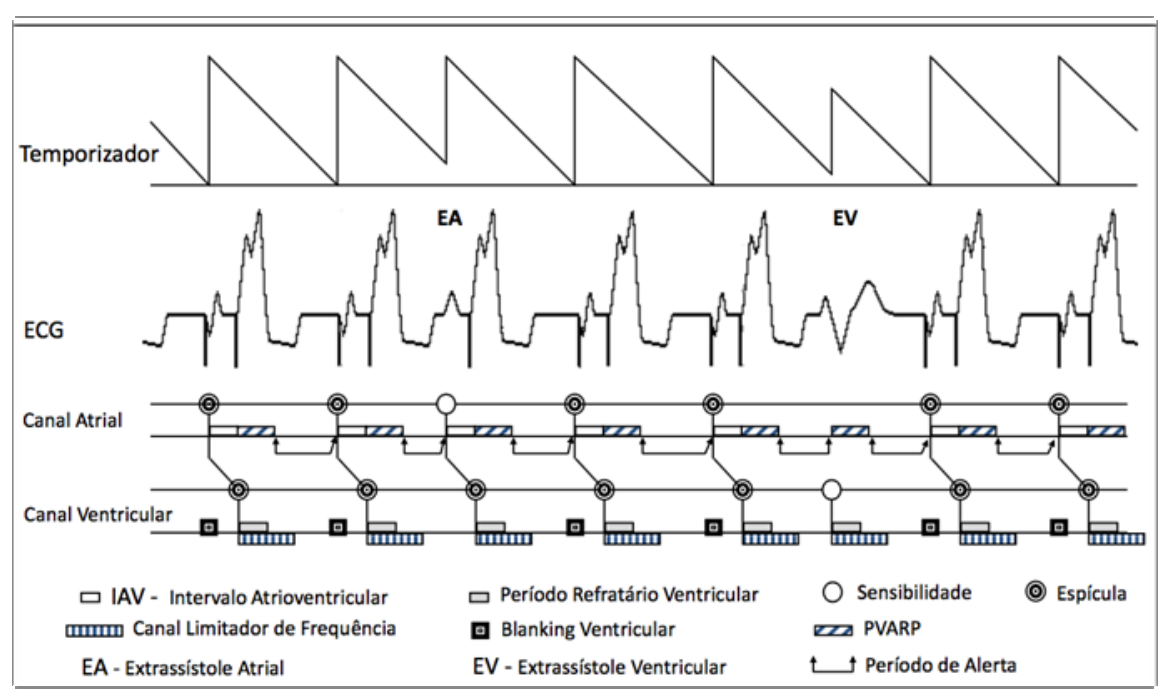

Fonte: Atlas de Marcapasso- Martinelli et al. ${ }^{7}$

Figura 4 - Diagrama do MODO DDD 


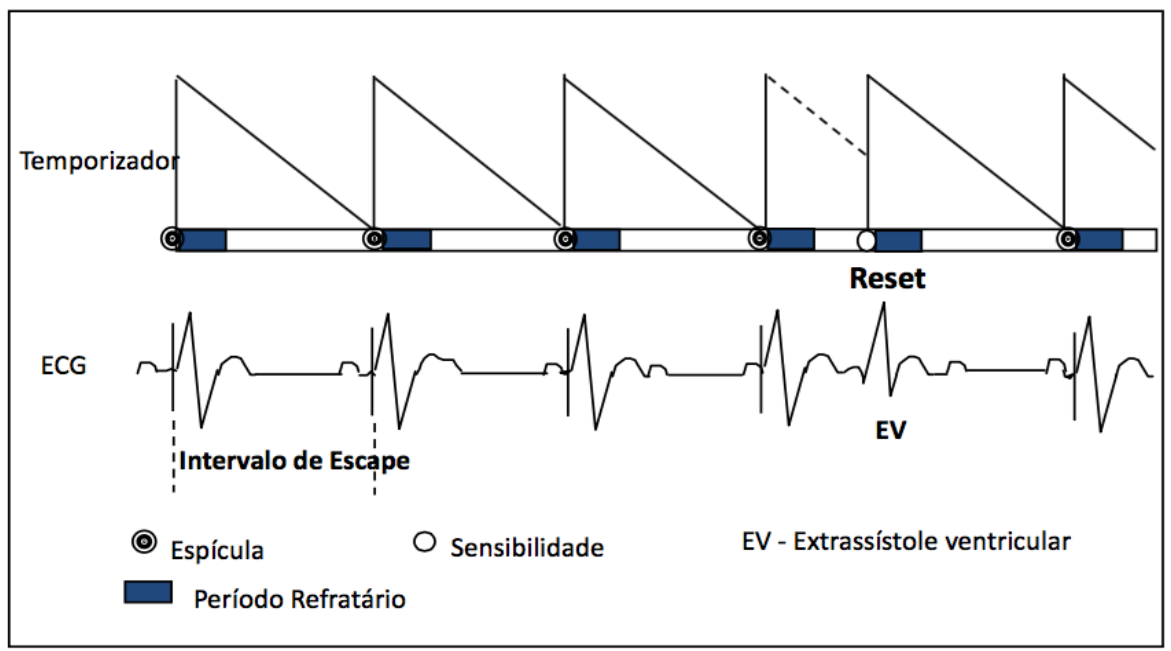

Fonte: Atlas de Marcapasso- Martinelli et al. ${ }^{7}$

Figura 5 - Diagrama do MODO VVI

A interpretação funcional do MCD depende do conhecimento básico de parâmetros e algoritmos, dentre os quais os mais relevantes são ${ }^{4,5}$ :

Potencial Endocavitário: sinal elétrico cardíaco próprio sentido pelo cabo-eletrodo a partir do local onde se encontra fixado;

Espícula do MCD: pulso de energia do MCD com amplitude (volts) e duração ou largura (milissegundos);

Captura ou potencial evocado: despolarização atrial ou ventricular provocada pela espícula do MCD;

Limiar de Sensibilidade: mínimo potencial elétrico endocavitário capaz de ser detectado pelo sistema;

Limiar de Captura ou Comando: mínima energia emitida capaz de provocar uma captura atrial ou ventricular;

Intervalo de Escape: intervalo de tempo entre as espículas (atrial ou ventricular) do MCD;

Frequência de Pulso: número de espículas (atrial ou ventricular) do MCD, durante o período de 60 segundos; 
Histerese: intervalo de tempo programável superior ao intervalo de escape acionado pela presença de um batimento próprio;

Intervalo AV: intervalo entre espícula atrial e ventricular;

Blanking Atrial: Período Refratário Atrial que corresponde ao período em que o gerador ignora qualquer potencial endocavitário atrial. Geralmente tem duração entre o início do intervalo AV até o final da onda T;

PVARP (Período Refratário Atrial Pós Evento Ventricular): intervalo pós-espícula ou evento ventricular no qual nenhum sinal endocavitário é sentido;

Sensor de Resposta de Frequência Cardíaca: algoritmo que modula a resposta de frequência de estimulação do MCD baseado nas informações do sensor para adequála às necessidades metabólicas e funcionais dos pacientes, podendo ser: Acelerômetro, Volume minuto e Closed Loop Stimulation (CLS), entre outros ${ }^{5}$.

\subsection{Resposta cardiovascular ao exercício}

A resposta cardiovascular ao esforço varia de acordo com o tipo, duração e intensidade da atividade física realizada, podendo implicar em hipertrofia miocárdica como mecanismo compensatório ao aumento da sobrecarga (pressão ou volume) imposta ao coração. Esta resposta adaptativa promove aumento do consumo de oxigênio $\left(\mathrm{VO}_{2}\right)$, que é a capacidade do organismo de captar, transportar e utilizar o oxigênio em nível periférico para a oxidação. $\mathrm{O} \mathrm{VO}_{2}$ está diretamente relacionado ao débito cardíaco (DC), com o conteúdo arterial de $\mathrm{O}_{2}$ e com a capacidade do tecido muscular em extrair o $\mathrm{O}_{2}$ durante o exercício físico ${ }^{8,9,10}$.

Os efeitos dos tipos de exercício conforme capacidade adaptativa são:

1- Exercício isométrico (exercício de força) - provoca aumento da frequência cardíaca (FC), da pressão arterial sistólica (PAS) e da pressão arterial diastólica (PAD), comparável à força máxima possível que um indivíduo pode evocar, denominada percentagem máxima de contração voluntária (MVC); provoca discreto aumento do $\mathrm{DC}$ e do $\mathrm{VO}_{2}{ }^{11,12,13}$. 
2- Exercício dinâmico de forte resistência (tal como levantamento de peso) dependendo da duração e da intensidade, a FC pode aumentar substancialmente e aproximar-se da $\mathrm{FC}_{\text {máx }}$ preconizada para a idade no teste ergométrico. As respostas de PAS e PAD também podem superar os valores atingidos durante o teste ergométrico ${ }^{11,12,14,15}$.

3- Exercício aeróbico-dinâmico (endurance) - ocorre aumento do $\mathrm{VO}_{2}$ e do DC, em virtude do aumento da FC paralelamente ao aumento do Volume Sistólico. Ocorre aumento concomitante da PAS associado à manutenção ou discreta queda da PAD. Com isso, há aumento discreto da PA média e queda da Resistência Vascular Periférica ${ }^{8,9,10,13,14,16,17 .}$

Com relação aos efeitos cardiovasculares do exercício aeróbico-dinâmico, deve-se considerar o tempo de realização e classificá-los como: agudos imediatos observados nos períodos pré, per e pós-imediato do exercício, promovendo aumento da FC, da PAS e sudorese associada ao esforço; agudos tardios - observados durante as $24 \mathrm{~h}$ ou $48 \mathrm{~h}$ (às vezes até $72 \mathrm{~h}$ ) após sessão de exercício, podendo provocar discreta redução dos níveis tensionais, expansão do volume plasmático, melhora da função endotelial e aumento da sensibilidade insulínica nas membranas das células musculares ${ }^{16,17,18,19}$.

Os efeitos crônicos do exercício, também denominados adaptações (bradicardia relativa de repouso, hipertrofia ventricular esquerda fisiológica e aumento do $\mathrm{VO}_{2}$ ), são resultados da frequência e regularidade às sessões de exercício, e são características morfofuncionais que distinguem o indivíduo treinado do sedentário ${ }^{8,20}$.

As alterações relacionadas à prática de exercício regular que promovem efeitos crônicos adaptativos são: remodelamento miocárdico, modulação da Resposta Autonômica e da resistência vascular periférica ${ }^{9,10,21}$.

Sabe-se que o $\mathrm{VO}_{2 \text { pico }}{ }^{22,23}$ é o principal indicador dessas adaptações e, provavelmente, o indicador isolado mais objetivo do nível de treinamento físico. Sabe-se também que, no adulto jovem, a taxa de $\mathrm{VO}_{2 \text { pico }}$ é determinante do nível de condicionamento físico: adulto jovem normal, não atleta, apresenta $\mathrm{VO}_{2 \text { pico }}$ estimado 
em $35 \mathrm{ml} / \mathrm{kg} / \mathrm{min}$ e atletas praticantes de exercício de resistência apresentam aumento médio de $50 \%$, podendo ultrapassar $70 \mathrm{ml} / \mathrm{kg} / \mathrm{min}^{24}$.

\subsection{Resposta pulmonar ao exercício}

A ação primordial do sistema respiratório é realizar as trocas gasosas necessárias para manter a oferta de $\mathrm{O}_{2}$ adequada às demandas metabólicas $\left(\mathrm{VO}_{2}\right)$, o que ocorre devido à maior sensibilidade às variações do $\mathrm{VCO}_{2}$, que promovem mudanças quase que imediatas do $\mathrm{pH}$ sistêmico. Durante as trocas gasosas para a produção de energia estão envolvidos quatro processos: 1. Ventilação pulmonar; 2. Perfusão pulmonar; 3. Transporte dos gases pelo sangue 4. Trocas gasosas nos capilares teciduais. Os dois primeiros processos são denominados de Respiração Externa e o último processo é classificado como Respiração Interna (Figura 6).

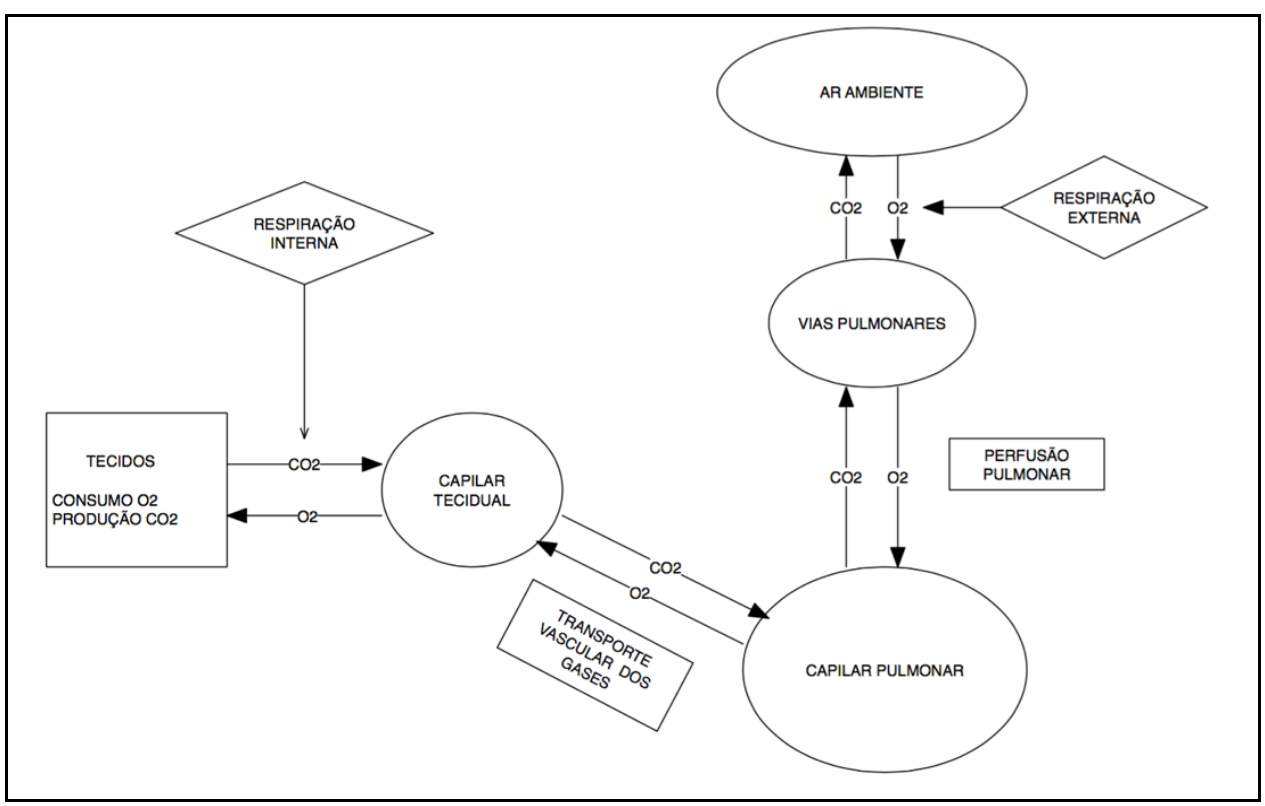

Fonte: Adaptado de Neder et al. ${ }^{22}$

Figura 6 - Diagrama representativo do Processo Respiratório. Nele estão descritos os processos respiratórios externos e internos 
O processo de respiração externa no início do exercício ocorre por aumento da ventilação estimulado por mecanismos neurais, com pequena queda da pressão expiratória final de oxigênio $\left(\mathrm{PETO}_{2}\right)$, uma vez que sobra menos $\mathrm{O}_{2}$ nos alvéolos, em função do aumento do consumo metabólico sem adequado aumento da oferta pela ventilação. Paralelamente, ocorre aumento da Pressão Parcial Expiratória de $\mathrm{CO}_{2}$ $\left(\mathrm{PETCO}_{2}\right)$ em função da maior quantidade de $\mathrm{CO}_{2}$ que começa a ser produzido no metabolismo, com maior eliminação através da ventilação que agora se acha otimizada. As trocas gasosas são, portanto, a base para essa produção energética. Seu mecanismo fisiológico deve levar em consideração a barreira alvéolo-pulmonar e as características de difusão dos gases $\mathrm{O}_{2}$ e $\mathrm{CO}_{2}$, que ocorrem de acordo com os seus gradientes de pressão ${ }^{22,24,26}$.

Durante o exercício contínuo, o estresse mecânico alveolar causado por altos níveis de ventilação e de fluxo sanguíneo alveolar podem afetar a permeabilidade da barreira alvéolo-pulmonar. Em repouso, são difundidos aproximadamente $250 \mathrm{ml}$ de $\mathrm{O}_{2}$ para os capilares e $200 \mathrm{ml}$ de $\mathrm{CO}_{2}$ na direção oposta ${ }^{24}$. Importante destacar que a capacidade de difusão pulmonar aumenta substancialmente com o exercício ${ }^{22,27}$.

Para compreendermos o processo de Respiração Externa, faz-se necessário inicialmente conhecer os Volumes Pulmonares, dentre os quais podemos destacar (Figura 7):

a. Volume Corrente (VC) - Volume de ar inspiratório e expiratório movimentado durante cada ciclo respiratório. Em repouso varia entre 0,4 a 1 litro de ar por incursão respiratória ${ }^{24}$.

b. Capacidade Vital (CV) - Volume de ar obtido durante a inspiração e a expiração forçadas. Será, portanto, o resultado do VC acrescido do volume de reserva inspiratória (VRI) e expiratória (VRE), também chamada de Capacidade Vital Forçada (CVF) e corresponde a 4 a 51 em homens sadios e 3 a 41 em mulheres sadias jovens $22,24,28$.

c. Volume Pulmonar Residual (VPR) - Volume de ar que permanece nos pulmões após exalar o mais profundamente possível. Oscila entre 0,8 a 1,2 1 em mulheres sadias e 0,9 a 1,4 1 para homens sadios jovens. O VPR aumenta com a idade enquanto o VRI e VRE diminuem proporcionalmente ${ }^{22,24,28 .}$ 
d. Capacidade Pulmonar Total (CPT) - Corresponde ao VPR e CVF.

e. Ventilação Minuto (V.E) - Corresponde ao volume de ar respirado a cada minuto, sendo portanto o resultado do produto da Frequência respiratória $(f)$ pelo (VC) ou seja $\left(V_{E}=V C x\right.$ f).

Durante o exercício físico, a capacidade de difusão pulmonar aumenta substancialmente assim como a capacidade de extração de $\mathrm{O}_{2}$. Entretanto, como o $\mathrm{VC}$ atinge um platô durante o exercício em aproximadamente $60 \%$ da $\mathrm{CV}$, a $\mathrm{V}_{\mathrm{E}}$ aumenta por um incremento proporcional da $\boldsymbol{f}$, com consequente maior ventilação alveolar para manter a correspondência ventilação-perfusão dentro da normalidade. Dessa maneira, em última análise os volumes pulmonares durante o esforço irão depender da Capacidade Vital (CV) e da Frequência Respiratória (f), sendo esta última intrinsicamente dependente da capacidade de difusão dos gases $22,24,28$.

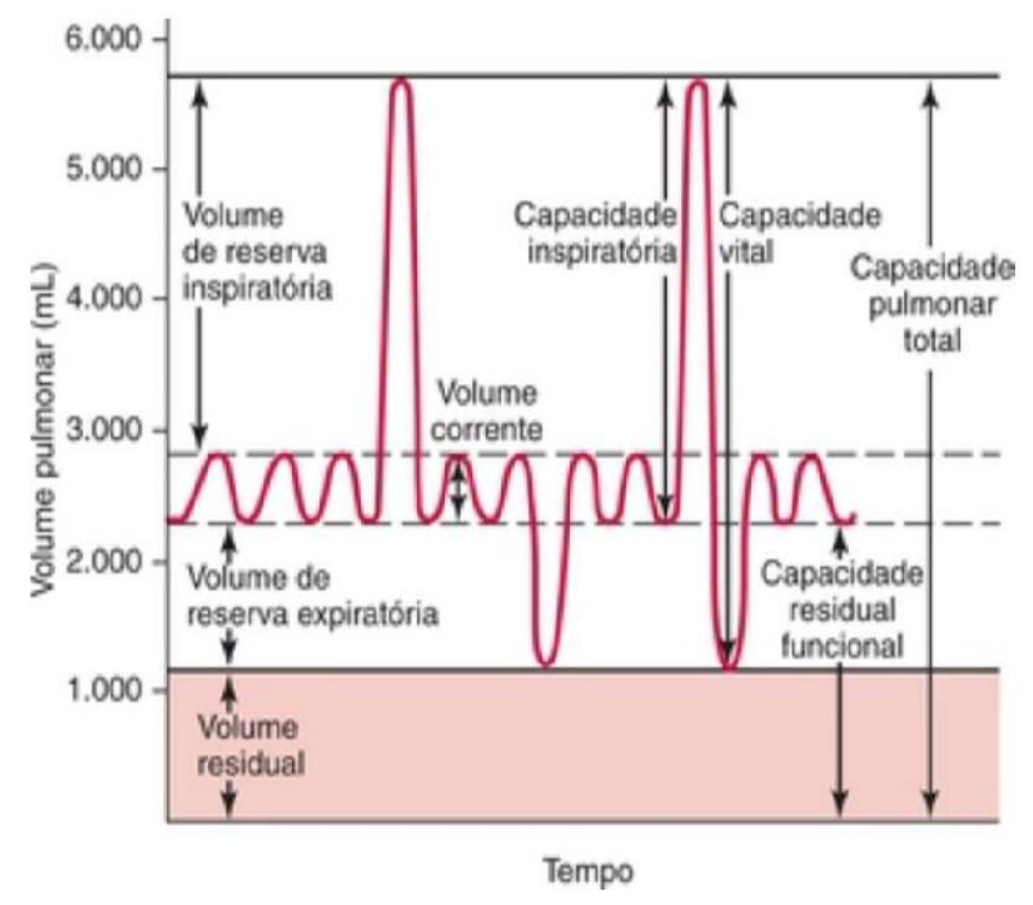

Fonte: Extraído de Frank et al. (Fisiologia do Exercício) ${ }^{24}$

Figura 7 - Gráfico representativo dos volumes pulmonares 
Equivalentes ventilatórios correspondem às razões entre a ventilação pulmonar e o consumo de $\mathrm{O}_{2}\left(\mathrm{VE} / \mathrm{VO}_{2}\right)$ e entre a ventilação pulmonar e a produção de $\mathrm{CO}_{2}\left(\mathrm{VE} / \mathrm{VCO}_{2}\right)$. Ambos são importantes na determinação dos limiares ventilatórios, sendo o $\mathrm{VE} / \mathrm{VCO}_{2}$ indicador do grau de eficiência ventilatória, uma vez que valores superiores a 34 em exercícios físicos realizados abaixo do Ponto de Compensação Respiratório, descritos a seguir, sugerem aumento da ventilação do espaço morto fisiológico $22,24,28,29$.

Pressões expiratórias finais correspondem às pressões alveolares médias de $\mathrm{O}_{2}\left(\mathrm{PETO}_{2}\right)$ e $\mathrm{CO}_{2}\left(\mathrm{PETCO}_{2}\right)$ durante a porção final da expiração, isto é, após o espaço morto anatômico. $\mathrm{O} \mathrm{PETCO}_{2}$ tem correlação positiva com o DC durante o exercício físico $^{22,24,28,29}$.

A respeito do processo de regulação da ventilação pulmonar durante o exercício, sugere-se que fatores reflexos corticais iniciem e elevem rapidamente a ventilação no início do exercício e que, em seguida, fatores humorais e neurogênicos modulem e promovam elevação mais lenta da ventilação. Depois disso ocorre um steady state na ventilação promovida por mecanorreceptores periféricos que modulam alterações físico-químicas. Ocorrem respostas mediadas por neurônios inspiratórios localizados na porção medial do Bulbo e de fatores humorais determinados por variações das pressões parciais dos gases respiratórios $\left(\mathrm{PO}_{2} \mathrm{e}\right.$ $\mathrm{PCO}_{2}$ ), pelas variações do $\mathrm{PH}$ e de temperatura. Estas sensibilizam o Bulbo via quimiorreceptores periféricos e ajustam a ventilação para manter o equilíbrio do $\mathrm{pH}$ e dos gases respiratórios $22,24,28,29$.

\subsection{Limiares metabólicos do exercício ${ }^{22,24,28,29,47}$}

Durante o início do esforço físico (20-30s iniciais) ocorre certo atraso no metabolismo aeróbico denominado déficit de $\mathrm{O}_{2}$, que é suprido pelos depósitos locais de fosfocreatina com produção temporária de ácido lático. Esse período é tanto mais curto quanto mais condicionado for o indivíduo. A partir daí as necessidades metabólicas aeróbicas serão supridas pelos sistemas cardiovascular e pulmonar. Para o correto entendimento do processo metabólico que ocorre durante o exercício, 
temos que compreender o resultado do processo de Respiração Interna já descrita acima, o qual ocorre pelos mecanismos Aeróbicos e Anaeróbicos. Para a sua correta definição e interpretação temos que definir os parâmetros Pico de $\mathbf{V O}_{2}$, Limiar Anaeróbico (LA) e Ponto de Compensação Respiratória (PCR), que são considerados padrão-ouro para a avaliação do metabolismo aeróbico e, portanto, para a avaliação e prescrição de exercícios.

À medida que a carga de trabalho se eleva, ocorre aumento linear proporcional do consumo de $\mathrm{VO}_{2}$ até que, num dado momento, por mais que se aumente o esforço físico o consumo de $\mathrm{VO}_{2}$ não mais aumentará, caracterizando o que se denomina $\mathbf{V O}_{2 \max }$. Na prática clínica, entretanto, a obtenção do $\mathrm{VO} 2_{\max }$ é rara e na maioria das vezes o que se obtém é o máximo de VO2 que o paciente consegue atingir durante o esforço o qual denomina-se $\mathrm{VO}_{2 \text { pico }}{ }^{22,23}$, sendo este o termo aqui preferencialmente adotado.

O Limiar Anaeróbico (LA) corresponde ao ponto de transição do exercício físico entre o metabolismo predominantemente aeróbico para o metabolismo predominantemente anaeróbio. A partir deste ponto as vias metabólicas de utilização de ATP são substituídas predominantemente por vias anaeróbicas.

Em indivíduos sedentários normalmente este limiar ocorre em torno de 45 a $65 \%$ do $\mathrm{VO}_{2 \text { máx }}$, já em atletas fica em torno de 80 a $90 \%$. Neste intervalo entre o LA até o PCR, o exercício físico ocorre com uma certa tolerância uma vez que os mecanismos metabólicos compensatórios conseguem manter o equilíbrio ácidobásico.

O Ponto de Compensação Respiratória (PCR) é o marco a partir do qual ocorre aumento contínuo na produção de lactato e $\mathrm{H}^{+}$excedendo a capacidade de regulação metabólica. Ocorre hiperventilação hipocápnica (acentuada taquipnéia) em resposta à acidose metabólica em curso e inicia-se a alcalose respiratória compensatória culminando com aumento do $\mathrm{VE} / \mathrm{VCO}_{2}$, queda progressiva da $\mathrm{PETCO}_{2}$ e aumento do $\mathrm{VE} / \mathrm{VO}_{2}$ e $\mathrm{PETO}_{2}$ até valores bem elevados. 


\subsection{Treinamento físico}

Antes de abordar as recomendações é essencial definir conceitos básicos: atividade física $^{25}$ - qualquer movimento da musculatura esquelética que resulta em gasto de energia corporal; exercícios físicos - atividade física planejada, estruturada e repetitiva, cujo objetivo é manter ou melhorar o condicionamento físico; tipos de programa de reabilitação - aparelho cardiovascular, musculatura esquelética, composição corporal, flexibilidade e neuro-muscular; dose de exercício: total de energia desprendida durante a atividade física; intensidade absoluta expressa em equivalente metabólico ou METS ( $\left.1 \mathrm{MET}=3,5 \mathrm{mlO}_{2} \mathrm{Kg}^{-1} \mathrm{~min}\right)$; intensidade relativa expressa em percentual da $\mathrm{FC}$ máxima ou percentual de $\mathrm{VO}_{2 \text { máx }}$ leve a moderada intensidade - consumo de até $40 \%$ do $\mathrm{VO}_{2 \text { máx }}$; moderada a alta intensidade consumo de $60 \%$ a $70 \%$ do $\mathrm{VO}_{2 \text { máx }}$; alta a severa intensidade - consumo de energia entre $70 \%$ a $80 \%$ do $\mathrm{VO}_{2 \text { máx }}$; severo a extremo - consumo superior a $80 \%$ do $\mathrm{VO}_{2 \text { máx }}$ (Figura 8) $2,30,31$.

O treinamento físico praticado regularmente atua na prevenção e no tratamento de doenças cardiovasculares ${ }^{1,32}$, depressão ${ }^{33}$, osteoporose ${ }^{34}$, hipertensão ${ }^{35,36}$ e câncer ${ }^{37}$, entre outras. Nesse sentido, a atividade física aeróbia é mais eficaz porque melhora a capacidade funcional e atua sobre o comportamento neuro-humoral protetor dos sistemas cardiorrespiratório e vascular.

A American Heart Association (AHA) define os seguintes requisitos para obtenção dos benefícios da atividade física: Intensidade - recomenda-se o limite de 50 a $80 \%$ do $\mathrm{VO}_{2 \text { máx }}$, sob reduzido nível de esforço no início do exercício, para pacientes de alto risco; intensidade superior a $85 \% \mathrm{VO}_{2 \max }$ proporciona benefícios modestos e aumenta riscos de arritmias cardíacas malignas; Frequência - duas a quatro vezes por semana, embora existam poucas evidências a esse respeito; Duração - entre 20 a 60 minutos de atividades aeróbicas são necessárias para melhorar a aptidão física e prevenir as doenças cardiovasculares. Nesse sentido, as recomendações do American College para Medicina esportiva ${ }^{13}$ indicam 30 minutos ou mais de atividade física de moderada intensidade de 5 a 7 dias por semana. 


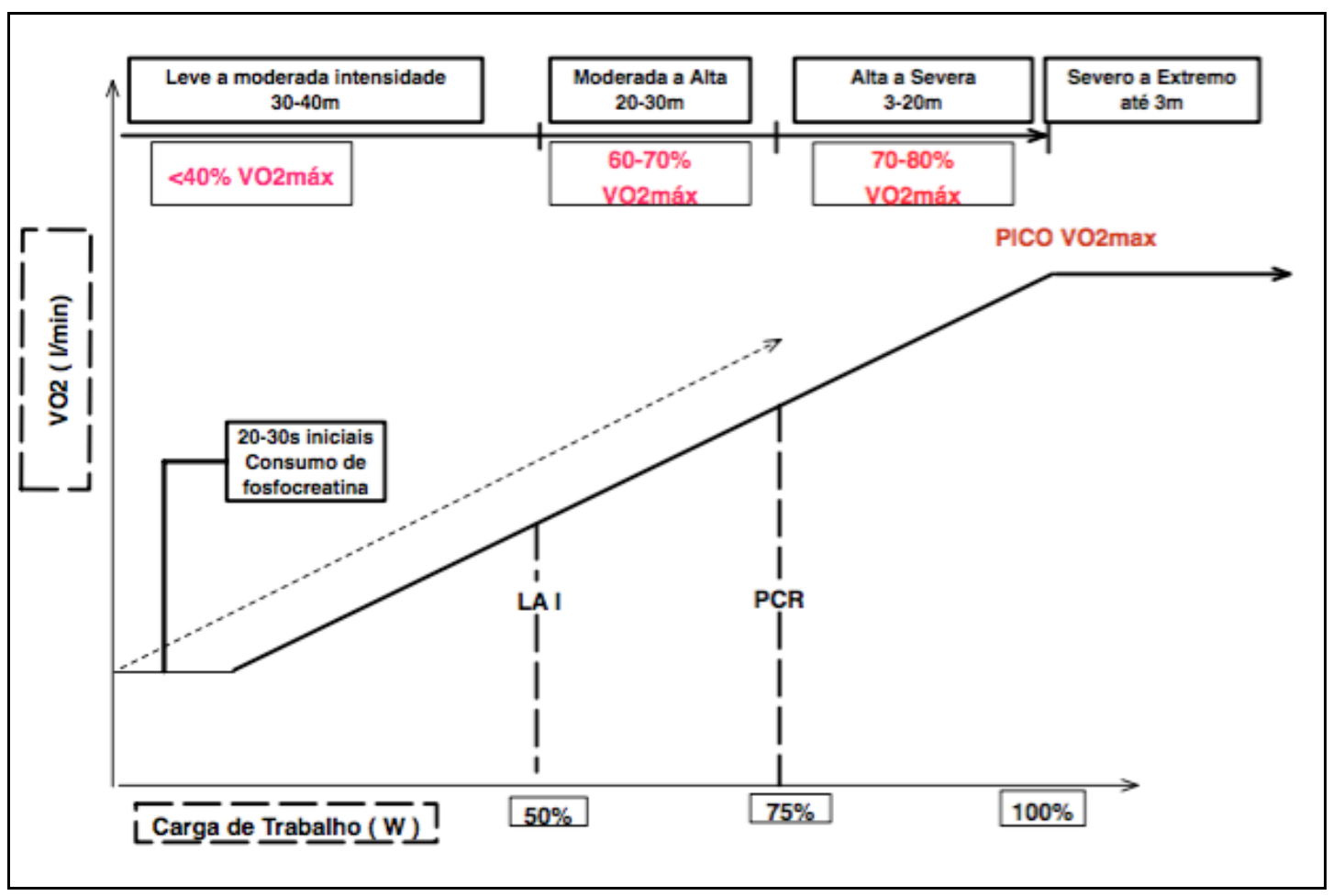

Fonte: Adaptado de Mezzani et al. ${ }^{31}$.

Figura 8 - Esquema representativo dos níveis de intensidade do exercício em relação ao $\mathrm{VO}_{2}$, em função da Carga de Trabalho

\subsection{Marcapasso e atividade física}

O estigma da incorporação de um DCEI costuma provocar insegurança a muitos pacientes e pode atuar como fator limitante de atividades físicas. A inatividade física, por sua vez, está associada a maior risco de ocorrência de doenças cardiovasculares, sobretudo em idosos ${ }^{1,38}$.

Os benefícios da atividade física em portadores de MCD foram pouco estudados. São baseados em estudos envolvendo grupos de pacientes praticando apenas atividades habituais e até o momento não se tem conhecimento de protocolos de treinamento físico para portadores de MCD.

Os obstáculos para elaboração de programas de treinamento físico em portadores de MCD esbarram na própria avaliação da capacidade funcional desses pacientes. Esta depende do tipo de dispositivo utilizado, do modo de estimulação 
(atrial, ventricular ou atrioventricular dupla câmara) e da presença de resposta cronotrópica própria ou determinada pelo sensor de resposta de frequência do dispositivo implantado.

A atividade física praticada por portadores de $\mathrm{MCD}$, além de melhorar o comportamento clínico, pode trazer marcantes benefícios psicológicos, promovendo a ressocialização de muitos pacientes.

Considerando que aproximadamente 12.000 idosos são submetidos a implante de DCEI no Brasil, ao ano ${ }^{39}$, na prática, o treinamento físico mais adequado seria a caminhada, uma atividade aeróbica muito bem aceita, que envolve grandes massas musculares acionadas de forma cíclica, e que promove melhora funcional coadjuvante ao tratamento convencional de doenças cardiovasculares. Recomenda-se, no mínimo, 30 minutos de exercício de baixa a moderada intensidade, com frequência de três a cinco vezes por semana ${ }^{1,30,32}$.

Assim, a falta absoluta de dados relativos aos efeitos adicionais do exercício físico regular sobre a população de portadores de MCD motivou a realização deste estudo. 
2 Objetivos do Estudo 


\section{OBJETIVOS DO ESTUDO}

1- Avaliar o impacto do treinamento físico, considerando protocolo supervisionado e não supervisionado, em portadores de MCD sem disfunção ventricular sobre o consumo de oxigênio e suas repercussões funcionais;

2- Estudar as correlações entre o consumo de oxigênio e a qualidade de vida. 


\section{Material e Métodos}




\section{MATERIAL E MÉTODOS}

PRACTICING (PHYSICAL TRAINING EFFECT IN PACEMAKER PATIENTS): Estudo prospectivo, randomizado, unicentro, com grupo controle.

Os pacientes foram selecionados na Unidade Clínica de Estimulação Cardíaca do Instituto do Coração (InCor) do Hospital das Clínicas da Universidade de São Paulo, seguindo a rotina pré-definida conforme o desenho do estudo - Figura 01 Anexo B.

\subsection{Critérios de inclusão}

Foram incluídos no estudo pacientes sedentários submetidos ao implante de MCD atrioventricular, há pelo menos três meses; sem disfunção sistólica do ventrículo esquerdo; com resposta cronotrópica adequada e com idade entre 18 e 80 anos.

\subsection{Critérios de exclusão}

Foram excluídos os pacientes praticantes de atividade física regular; com ICC, doenças musculoesqueléticas, pulmonares ou neurológicas que não permitam a participação em programa de exercício, insuficiência renal moderada ou grave; arritmias atriais sustentadas; portadores de cardioversor-desfibrilador implantável (CDI) ou de Ressincronizador Cardíaco, e MCD com indicação de troca de gerador por desgaste de bateria.

Todos os pacientes foram previamente esclarecidos acerca do protocolo e assinaram Termo de Consentimento Livre e Esclarecido (Anexo A) antes de iniciarem as atividades da pesquisa. 


\subsection{Abordagens diagnósticas}

Foram realizadas duas abordagens diagnósticas com intervalo de 4 meses, que incluíram avaliação clínico-laboratorial, aplicação de Questionários de Qualidade de Vida - (QdV) SF-36 ${ }^{40}$ e Aqualrel ${ }^{41}$, e realização de Avaliação Cardiopulmonar em Esforço (ACE).

\subsection{Avaliação clínico-laboratorial}

A avaliação constou de anamnese, exame físico, terapêutica medicamentosa administrada, dos exames bioquímicos e dos seguintes exames complementares: ECG de 12 derivações, Holter de 24h e Ecocardiograma Transtorácico.

Também foram incluídas a avaliação da programação eletrônica do MCD que constou de obtenção dos limiares de estimulação cardíaca artificial, dos potenciais intracavitários e dos percentuais de sensibilidade e estimulação cardíaca artificial no átrio e ventrículo. Em seguida procedemos os ajustes nos seguintes parâmetros eletrônicos do MCD: FC basal de 60 bpm, FCmáx (Up-rate) superior a 140 bpm, ajuste do Delay AV e PVARP. No que tange à utilização do sensor de resposta de frequência cardíaca (R), optamos por mantê-lo desativado uma vez que nossos pacientes apresentam resposta cronotrópica normal.

Objetivou-se a operação do MCD em modo VAT, isto é, Sense Atrial e Pace Ventricular, com condução 1:1 em mais de 90\% do período do estudo, visando a obtenção de teste máximo para todos os pacientes ${ }^{42}$.

\subsection{Questionários de Qualidade de Vida- SF-36 e Aquarel}

Vários são os questionários de Qualidade de Vida (QdV) utilizados na Literatura. A grande preocupação na utilização de todos é que basicamente foram desenvolvidos em língua inglesa e carecem, portanto, de uma tradução que seja capaz de se aproximar, ao máximo, do contexto cultural no país em que será aplicado. Diante disso utilizamos o SF-36 ${ }^{40,43}$ (Medical Outcomes Study 36- Item 
Short-Form Health Survey) e o Aquarel ${ }^{41,43,44,45,46}$ (Assesment of Quality of Life and Related Events) por sua ampla aplicabilidade e por apresentarem versão para a língua portuguesa. Em seguida os pacientes foram orientados a, espontaneamente, responder aos questionários de QdV genérico SF-36 e o específico Aquarel. Os dados obtidos foram inseridos no Banco de Dados REDCap (Research Electronic Data Capture - é uma aplicação Web segura para a construção e gestão de pesquisas online e bancos de dados da Vanderbilt University) e os resultados das médias foram exportados em planilha Excel, por cada domínio do SF-36 e do Aquarel.

SF-36 - Trata-se de questionário relativamente simples de aplicabilidade, de uso genérico, formado por 36 itens, englobados em oito escalas ou componentes, a saber: Capacidade Funcional, Aspectos Físicos, Dor, Saúde Geral, Vitalidade, Aspectos Sociais, Aspectos Emocionais, Saúde Mental, Sumário Saúde Física e Sumário Saúde Mental, sendo o 0 (zero) correspondente ao pior estado geral de saúde e 100 (cem) ao melhor estado de saúde.

Aquarel - De uso específico para a avaliação de QdV em portadores de MCD, com adaptação cultural e versão em língua portuguesa. O Aquarel é composto por vinte questões distribuídas em três domínios: desconforto no peito, dispneia ao esforço, arritmia, tendo sido desenvolvido para complementar o uso de SF-36 em portadores de MCD.

\subsection{Avaliação Cardiopulmonar em Esforço}

Previamente à realização da Avaliação Cardiopulmonar em Esforço (ACE), também denominada Teste Ergoespirométrico, foi realizado o ECG de repouso de 12 derivações simultâneas (Micromed - Cardio PC 13). A pressão arterial de repouso foi medida pelo método auscultatório, com o indivíduo na posição sentada. Em seguida, sob monitoração eletrocardiográfica contínua, foi realizada ACE, para avaliação da capacidade funcional (SensorMedics - Vpico Analyzer Assembly, Encore 29S), em esteira ergométrica (Ergoline - Via Sprint 150 P), precedido da calibração do equipamento pelas normas da BTPS (body temperature pressure satured) e STPD (standard temperature pressure and dry), que corresponde a $0^{\circ} \mathrm{C}$ de 
temperatura, pressão de $760 \mathrm{mmHg}$ ao nível do mar e em condições de ausência de vapor de água, ou seja, seco ${ }^{29}$.

A ACE utilizou o protocolo de Balke ${ }^{29,47}$ modificado que é constituído por aumento constante de velocidade de 2,0 a 3,4 mph com inclinação de $2 \%$ a cada minuto até exaustão. A frequência cardíaca foi registrada em repouso com o indivíduo posicionado na esteira rolante e ao final de cada minuto do esforço assim

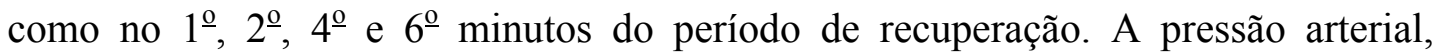
medida sempre pelo mesmo avaliador, em repouso, foi obtida nos 30 segundos finais a cada dois estágios do exercício e no $1^{\underline{0}}, 2^{\underline{O}}, 4^{\underline{O}}$ e $6^{\underline{0}}$ minutos do período de recuperação.

A Capacidade Funcional Máxima (CFM) foi determinada pelo consumo de oxigênio de pico $\left(\mathrm{VO}_{2 \text { pico }}\right)$, avaliado na intensidade máxima de exercício ${ }^{29,47,48}$.

O Limiar Anaeróbio (LA) foi determinado no momento em que o paciente apresentava o menor valor de equivalente ventilatório de $\mathrm{O}_{2}\left(\mathrm{VE} / \mathrm{VO}_{2}\right)$ e Pressão Parcial de oxigênio no final da expiração $\left(\mathrm{PETO}_{2}\right)$, antes que esses parâmetros iniciassem um aumento progressivo e incremento não linear do valor de razão de troca respiratória (RER ou RQ) ${ }^{22,26,29,31,47 .}$

O Ponto de Compensação Respiratória (PCR) foi determinado no minuto em que o paciente apresentou o menor valor de equivalente ventilatório de $\mathrm{CO}_{2}$ $\left(\mathrm{VE} / \mathrm{VCO}_{2}\right)$, antes que esse parâmetro iniciasse um aumento progressivo, e simultaneamente, o máximo valor de Pressão Parcial de $\mathrm{CO}_{2}$ no final da expiração $\left(\mathrm{PETCO}_{2}\right)$, antes de iniciar uma queda progressiva ${ }^{22,26,29,31}$.

\subsection{Pacientes e randomização}

Após abordagem diagnóstica, ajustes de programação do MCD e realização do ACE, os pacientes foram incluídos na lista de randomização.

A randomização constou de lista de sequência aleatória obtida por software específico, sendo realizada por um observador alheio ao protocolo. 
Todos os esforços foram realizados para se evitar mudança de grupos (crossover).

A estimativa de inclusão foi de 60 pacientes a serem randomizados em:

1- Grupo de Treinamento Físico Supervisionado (GTFS);

2- Grupo de Treinamento Físico Não Supervisionado (GTFNS);

3- Grupo controle (GC) (Anexo B - Figura 1).

\subsection{Atividades dos Grupos de Estudo}

Os pacientes do GC não realizaram qualquer protocolo de treinamento físico.

Os pacientes dos GTFS e GTFNS foram submetidos a programas de treinamento físico planejados pela Unidade de Reabilitação Cardiovascular do Instituto do Coração (InCor-SP), conforme protocolos institucionais.

O GTFS recebeu o treinamento por 4 meses com periodicidade de três vezes por semana. A intensidade do exercício foi definida pelos valores intermediários do Limiar Anaeróbico (LA) ao Ponto de Compensação Respiratória (PCR), obtidos na primeira ACE (avaliação basal). Cada sessão teve duração de 50 minutos, sendo 5 minutos de aquecimento com exercícios de alongamento muscular, 40 minutos de exercício aeróbico, em esteira rolante, e 5 minutos de relaxamento ${ }^{22,31,49}$. Ao final de cada treino os pacientes informaram sobre a intensidade do exercício pela escala de Borg ${ }^{50}$.

No GTFNS, os exercícios foram planejados levando-se em conta os dados da ACE basal e a intensidade do exercício determinada individualmente entre o LA e o PCR. As atividades deste grupo foram orientadas na Unidade de Reabilitação-InCor e realizadas em ambiente escolhido pelos próprios pacientes. A aderência aos exercícios foi acompanhada por meio de formulário fornecido pela Unidade de Reabilitação - InCor e preenchido pelos pacientes nos dias das atividades. Dados como frequência cardíaca (FC) de repouso e durante o exercício também foram exigidos e serviram para monitoração da aderência, intensidade e frequência de realização dos exercícios. Nesse sentido, todos os pacientes foram orientados para a 
correta medição da FC (basal e em atividade) assim como para o adequado preenchimento da avaliação da intensidade do exercício realizado, por meio da escala de Borg ${ }^{50}$. Todos os pacientes desse grupo assumiram o compromisso de retornarem à Unidade de Reabilitação - InCor, ao final de cada mês, com os formulários devidamente preenchidos para avaliação da aderência ao treinamento orientado.

\subsection{Análise estatística}

As variáveis contínuas analisadas foram os parâmetros da ACE e da Resposta cardiovascular ao esforço, além dos questionários de QdV SF-36 e Aquarel. Todas foram expressas em médias e desvio-padrão, e submetidas a Testes de Normalidade de Shapiro-Willk, assim como as variáveis categóricas foram expressas como frequências relativas.

Para analisar as diferenças nas variáveis contínuas entre os momentos inicial e final, foi aplicado o teste de ANOVA para Medidas Repetidas para a comparação dos três grupos no momento inicial e intra-grupos nos momentos pré e póstreinamento físico. Além disso, foram realizadas análises entre os grupos e intragrupos levando-se em consideração as variáveis sexo, peso, morbidade e uso de medicamentos. Realizamos ainda testes de Correlação de Sperman entre o $\mathrm{VO}_{2 \text { máx }}$ da CFM e os questionários QvD nos momentos pré entre os grupos e pré e pós treinamento físico intra grupos.

O cálculo do tamanho da amostra foi dificultado pela ausência de estudos na literatura avaliando os efeitos do treinamento físico nos portadores de MCD. Assim, utilizou-se como base o estudo de Stratton et al. ${ }^{38}$, que avaliou os efeitos do treinamento físico em jovens e idosos sadios. A variável utilizada foi o consumo máximo de oxigênio que apresentou $21 \%$ no grupo de idosos $(28,9 \pm 4,6$ a $35,1 \pm 3,8$ $\mathrm{mL} / \mathrm{kg} \min , P<0,001)$ e $17 \%$ no grupo de jovens $(44,5 \pm 5,1$ a $52,1+6,3 \mathrm{~mL} / \mathrm{kg} \mathrm{min}$, $P<0,001)$.

Considerando a menor variação (entre jovens) pode-se definir o número de 15 pacientes para cada grupo, utilizando 5\% de nível de significância, poder de $90 \%$ e 
hipótese bicaudal. Com as perdas para cada grupo, estimadas em 10\%, optamos por randomizar 20 pacientes para cada grupo. 
4 Resultados 


\section{RESULTADOS}

\subsection{Características da amostra}

Dentre os 182 pacientes avaliados, 37 se recusaram a realizar o protocolo, 20 foram excluídos por apresentarem disfunção sistólica do VE, ao Ecocardiograma Transtorácico, 17 não tinham condições de realizar atividades físicas, nove residiam em outros municípios, quatro participavam de outros protocolos, quatro já realizavam atividades físicas, 15 tinham baixo percentual de estimulação ventricular, nove desencadearam ritmo próprio a $\mathrm{ACE}$, quatro apresentaram incompetência cronotrópica, três tinham disfunção do MCD e dois apresentavam arritmias cardíacas (Figura 9).

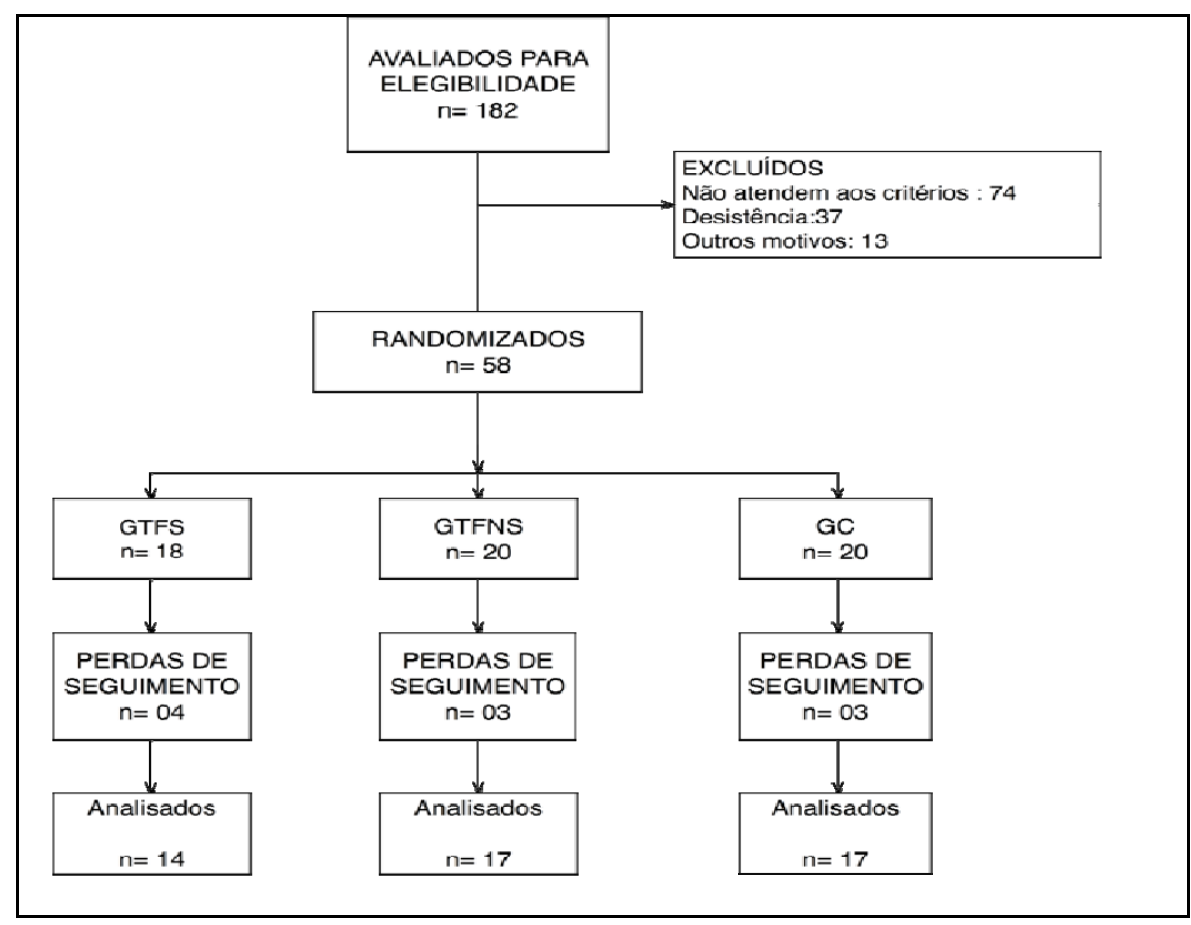

Figura 9 - Fluxograma do estudo incluindo a casuística por grupo, conforme randomização 
Os grupos ficaram assim constituídos:

GTFS com 18 inclusões, correspondendo ao tempo médio de implante de MCD de $56,7 \pm 47,6$ meses. Neste grupo ocorreram quatro perdas de seguimento e 14 pacientes

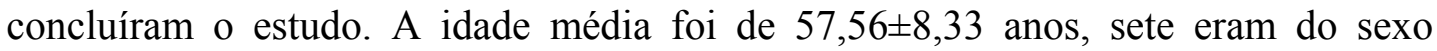
masculino e peso médio era de $79,11 \pm 14,71 \mathrm{Kg}$, obtendo-se uma aderência média de $89,7 \pm 20,2 \%$

GTFNS com 20 inclusões, correspondendo ao tempo médio de implante de MCD de $83 \pm 85$ meses. Neste grupo ocorreram três perdas de seguimento e 17 pacientes concluíram o estudo. A idade média foi de 54,2 $\pm 12,71$ anos, quatro pacientes eram do sexo masculino e o peso médio era de $69,81 \pm 13,40 \mathrm{Kg}$, obtendo-se uma aderência média de $81,6 \pm 47 \%$.

GC com 20 inclusões, correspondendo ao tempo médio de implante de MCD de $42,5 \pm 38$ meses. Neste grupo ocorreram três perdas de seguimento e 17 pacientes

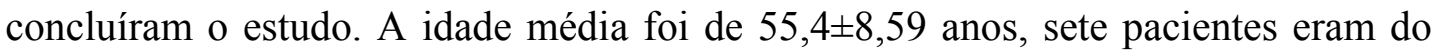
sexo masculino e o peso médio era de $67,73 \pm 13,25 \mathrm{Kg}$.

Portanto, a análise final do estudo envolveu 58 pacientes, sendo 18 homens e 40 mulheres, com idade média de 55,75 $\pm 10,0$ anos, peso médio de $72 \pm 14,4 \mathrm{Kg}$ e

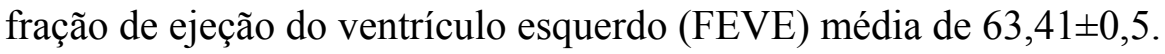

As indicações para MCD foram: BAV $2^{\circ}$ Grau em cinco pacientes $(8,62 \%)$; BAV 2:1 em sete pacientes (12,07\%) e BAVT em 46 pacientes $(79,31 \%)$.

As características clínicas dos pacientes do estudo estão incluídas na Tabela 2. Destaque-se a presença de HAS em aproximadamente $59 \%$ dos pacientes, de Dislipidemia em 31\%, e Diabetes Mellitus em 26\%. 
Tabela 2 - Características clínico-funcionais basais da casuística

\begin{tabular}{|c|c|}
\hline VARIÁVEIS & Distribuição \\
\hline \multicolumn{2}{|l|}{ Gênero - n(\%) } \\
\hline Feminino & $40(68,97)$ \\
\hline Idade - anos (média \pm DP $)$ & $55,7 \pm 10,00$ \\
\hline Peso $-\mathrm{Kg}($ média $\pm \mathrm{DP})$ & $72,0 \pm 14,40$ \\
\hline \multicolumn{2}{|l|}{ Cardiopatia de Base - n(\%) } \\
\hline Chagásica & $16(27,5)$ \\
\hline Isquêmica & $1(1,7)$ \\
\hline Sem cardiopatia estrutural & $41(70,6)$ \\
\hline \multicolumn{2}{|l|}{ Comorbidades $-\mathrm{n}(\%)$} \\
\hline HAS & $34(58,62)$ \\
\hline Dislipidemia & $18(31,03)$ \\
\hline Diabetes Melitus & $15(25,86)$ \\
\hline Hipotireoidismo & $3(5,17)$ \\
\hline \multicolumn{2}{|l|}{ Medicamentos- $\mathrm{n}(\%)$} \\
\hline IECA & $17(29,31)$ \\
\hline BRA & $8(13,79)$ \\
\hline Beta - bloqueador & $13(22,41)$ \\
\hline AAS & $15(25,86)$ \\
\hline Hipoglicemiante Oral & $15(25,86)$ \\
\hline Diurético & $21(36,21)$ \\
\hline Estatina & $14(24,14)$ \\
\hline \multicolumn{2}{|l|}{ Indicações de MCD - n(\%) } \\
\hline $\mathrm{BAV} 2^{\circ} \mathrm{Grau}$ & $5(8,62)$ \\
\hline BAV $2^{\circ}$ Grau 2:1 & $7(12,07)$ \\
\hline BAV $3^{\circ}$ Grau (BAVT) & $46(79,31)$ \\
\hline FEVE ao Ecocardiograma (média $\pm \mathrm{DP}$ ) & $0,64 \pm 0,05$ \\
\hline \multicolumn{2}{|l|}{$\mathrm{ACE}-\operatorname{VO} 2(\mathrm{ml} / \mathrm{Kg} / \mathrm{min})($ média $\pm \mathrm{DP})$} \\
\hline VO2 CFM & $24,0 \pm 5,2$ \\
\hline $\mathrm{VO}_{2} \mathrm{LA}$ & $17,1 \pm 3,7$ \\
\hline $\mathrm{VO}_{2} \mathrm{PCR}$ & $21,0 \pm 5,2$ \\
\hline Tempo Médio de implante de MCD - meses (média \pm DP) & $59,56 \pm 62,6$ \\
\hline
\end{tabular}

Legendas: HAS -Hipertensão Arterial Sistêmica; IECA -inibidor enzima conversora de angiotensina; BRA bloqueador do receptor da angiotensina II; AAS - ácido acetil salicílico; MCD - marcapasso cardíaco definitivo; BAV - bloqueio atrioventricular; BAVT - bloqueio atrioventricular total; $\mathbf{V O}_{2^{-}}$consumo de oxigênio; LA liminar anaeróbico; PCR -ponto de compensação respiratória; FEVE - fração de ejeção do ventrículo esquerdo. DP - Desvio padrão - ACE- avaliação cardiopulmonar ao esforço 


\subsection{Análise de resultados}

\subsubsection{Avaliação de homogeneidade entre os grupos}

A análise comparativa das características clínico-funcionais basais entre os grupos demonstrou que não houve diferença significativa em relação às variáveis idade e gênero, entretanto, a variável peso foi significativamente superior no GTFS. Com relação à FEVE, variáveis da $\mathrm{ACE}$ e às comorbidades HAS, dislipidemia, diabetes mellitus e hipotireoidismo também não houve diferença estatística entre os grupos. Da mesma forma, a análise comparativa relativa ao uso de IECA, AAS, hipoglicemiante oral, diuréticos e estatina não demonstrou diferença estatística entre os grupos. (Tabela 3). 
Tabela 3 - Análise comparativa das características clínico-funcionais basais entre os grupos

\begin{tabular}{|c|c|c|c|c|}
\hline VARIÁVEL & $\begin{array}{l}\text { GTFS } \\
n=18\end{array}$ & $\begin{array}{c}\text { GTFNS } \\
\mathbf{n}=\mathbf{2 0}\end{array}$ & $\begin{array}{c}\text { GC } \\
\mathbf{n}=\mathbf{2 0}\end{array}$ & $p$ \\
\hline Idade (anos) & $57,56 \pm 8,33$ & $54,20 \pm 12,71$ & $55,40 \pm 8,59$ & 0,592 \\
\hline Peso corporal (Kg) & $79,11 \pm 14,71$ & $69,81 \pm 13,40$ & $67,73 \pm 13,25$ & 0,033 \\
\hline \multicolumn{5}{|l|}{ Gênero - n(\%) } \\
\hline Masculino & $10(55,6)$ & $4(20)$ & $8(40)$ & \multirow[t]{2}{*}{0,076} \\
\hline Feminino & $8(44,4)$ & $16(80)$ & $12(60)$ & \\
\hline \multicolumn{5}{|l|}{ Ecocardiograma } \\
\hline DDVE (mm) & $48,12 \pm 6,59$ & $46,89 \pm 13,19$ & $46,53 \pm 6,92$ & 0,873 \\
\hline DSVE (mm) & $32,56 \pm 6,86$ & $29,26 \pm 7,86$ & $31,63 \pm 3,30$ & 0,268 \\
\hline FEVE (\%) & $0,63 \pm 0,06$ & $0,64 \pm 0,04$ & $0,64 \pm 0,05$ & 0,809 \\
\hline \multicolumn{5}{|l|}{ ACE (CFM) } \\
\hline Carga de Trabalho (Watts) & $134,89 \pm 48,20$ & $126,42 \pm 38,21$ & $121,58 \pm 44,65$ & 0,642 \\
\hline VO2pico (ml/Kg/min) & $23,17 \pm 4,17$ & $24,96 \pm 5,13$ & $23,81 \pm 0,32$ & 0,576 \\
\hline $\mathrm{VO} 2$ pico predito $(\mathrm{ml} / \mathrm{Kg} / \mathrm{min})$ & $92,22 \pm 22,16$ & $91,65 \pm 15,56$ & $88,05 \pm 21,24$ & 0,776 \\
\hline VO2 Pulso (ml/Kg/min) & $12,37 \pm 3,60$ & $11,43 \pm 2,62$ & $10,58 \pm 2,68$ & 0,191 \\
\hline VO2 RQ & $1,14 \pm 0,11$ & $1,14 \pm 0,11$ & $1,14 \pm 0,07$ & 0,995 \\
\hline \multicolumn{5}{|l|}{ Medicamentos - n(\%) } \\
\hline IECA & $13(72,2)$ & $13(65,0)$ & $15(75,0)$ & 0,512 \\
\hline BRA & $16(88,9)$ & $17(85,0)$ & $16(80,0)$ & 0,900 \\
\hline Beta -bloqueador & $15(83,3)$ & $13(65,0)$ & $16(80,0)$ & 0,408 \\
\hline AAS & $14(77,8)$ & $15(75,0)$ & $14(70,0)$ & 0,310 \\
\hline Hipoglicemiante Oral & $15(83,3)$ & $17(85,0)$ & $17(85,0)$ & 1,000 \\
\hline Diurético & $10(55,6)$ & $14(70,0)$ & $13(65,0)$ & 0,875 \\
\hline Estatina & $12(66,7)$ & $16(80,0)$ & $16(80,0)$ & 0,590 \\
\hline \multicolumn{5}{|l|}{ Comorbidades - n(\%) } \\
\hline Diabetes Mellitus & $6(33,3)$ & $4(20,0)$ & $5(25,0)$ & 0,890 \\
\hline Hipertensão Arterial & $11(61,1)$ & $10(50,0)$ & $13(65,0)$ & 0,994 \\
\hline \multicolumn{5}{|l|}{ Cardiopatia de base - n(\%) } \\
\hline Chagásica & $5(27,8)$ & $4(20)$ & $7(35)$ & \multirow{3}{*}{0,491} \\
\hline Isquêmica & $1(5,6)$ & $0(0)$ & $0(0)$ & \\
\hline Sem cardiopatia estrutural & $12(66,7)$ & $16(80)$ & $13(65)$ & \\
\hline
\end{tabular}

Obs: média \pm DP; Frequência absoluta (porcentagem simples).

Legendas: IECA -inibidor enzima conversora de angiotensina; BRA - bloqueador do receptor da angiotensina II; AAS - ácido acetil salicílico; MCD - marcapasso cardíaco definitivo; BAV - bloqueio atrioventricular; $\mathbf{V O}_{2^{-}}$ consumo de oxigênio; FEVE - fração de ejeção do ventrículo esquerdo. DP - desvio padrão; ACE- avaliação cardiopulmonar ao esforço 


\subsubsection{Parâmetros da Avaliação Cardiopulmonar em Esforço}

\section{$\mathrm{VO}_{2 p i c o}$ e Carga de Trabalho (watts)}

A análise comparativa do $\mathrm{VO}_{2 \text { pico }}$ (CFM) entre momentos pré e pós demonstrou aumento significativo (12,07\%) no GTFS $(23,86 \pm 4,39$ x 26,74 $\pm 4,18$ $p: 0,001)$.

Com relação à carga de trabalho (watts), ocorreu aumento significativo entre os momentos pré e pós, intra-grupos $(P<0,001)$, sendo que no GTFS o aumento foi de 29\% (145,19 para 188,20 watts), no GTFNS foi de 16\% (124,86 para 144,89 watts) e no GC de $11 \%$ (125,08 para 139,61 watts). A análise comparativa entre grupos demonstrou que o incremento de carga no GTFS foi superior em relação aos demais (GTFS x GTFNS $P=0,009$ e GTFS x GC $P=0,041$ ). Não houve diferenças entre GTNS e o GC, considerando os momentos pré e pós. (Tabela 4, Figura 10).

Tabela 4 - Análise comparativa entre os momentos Pré x Pós da Carga e Voomáx do TEE

\begin{tabular}{|c|c|c|c|c|c|c|}
\hline VARIÁVEL & $\begin{array}{c}\text { GTFS } \\
\text { (Média } \pm D P \text { ) }\end{array}$ & $\begin{array}{c}\text { GTFNS } \\
(\text { Média } \pm D P)\end{array}$ & $\begin{array}{c}\text { GC } \\
(\text { Média } \pm D P)\end{array}$ & $\begin{array}{c}P \\
\text { GTFS } \\
\text { vs } \\
\text { GTFNS }\end{array}$ & $\begin{array}{c}P \\
\text { GTF } \\
\text { S vs } \\
\text { GC }\end{array}$ & $\begin{array}{c}P \\
\text { GTFN } \\
\text { S vs } \\
\text { GC }\end{array}$ \\
\hline \multicolumn{7}{|c|}{ Carga CFM - Watts } \\
\hline Pré & $145,19 \pm 44,02$ & $124,86 \pm 37,69$ & $125,08 \pm 47,34$ & \multirow{3}{*}{$<0,01$} & \multirow{3}{*}{0,04} & \multirow{3}{*}{0,85} \\
\hline Pós & $188,20 \pm 46,53$ & $144,89 \pm 37,87$ & $139,61 \pm 55,32$ & & & \\
\hline$p$ & 0,001 & 0,001 & 0,001 & & & \\
\hline \multicolumn{7}{|c|}{ VO2Pico CFM - ml/Kg/min } \\
\hline Pré & $23.86 \pm 4.39$ & $25.02 \pm 5.40$ & $24,52 \pm 6,59$ & \multirow{3}{*}{0,718} & \multirow{3}{*}{0,718} & \multirow{3}{*}{0,718} \\
\hline Pós & $26.74 \pm 4.18$ & $25.39 \pm 6.56$ & $24,42 \pm 5,78$ & & & \\
\hline$p$ & $<0,01$ & 0,81 & 0,81 & & & \\
\hline
\end{tabular}

Legendas: $\mathbf{V O}_{2}$ - consumo de oxigênio; $\mathbf{C F M ~ - ~ c a p a c i d a d e ~ f u n c i o n a l ~ m a ́ x i m a ; ~} \mathbf{D P}$ - desvio padrão. 


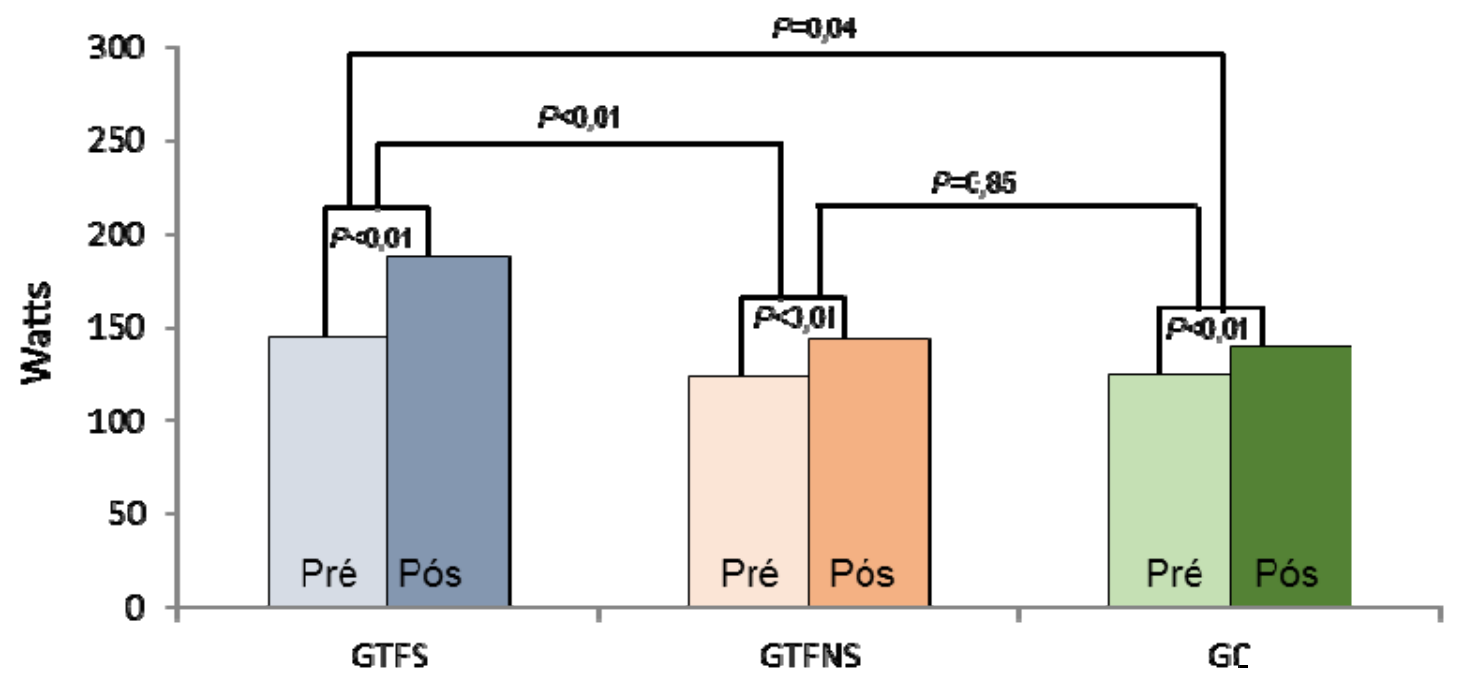

Figura 10 - Análise comparativa entre os momentos Pré x Pós da Carga e $\mathrm{Vo}_{2 \text { máx }}$ do TEE nos três grupos

\section{Pulso de $\mathrm{O}_{2}$ e RQ}

A análise comparativa dos resultados do Pulso de $\mathrm{O}_{2}$ demonstrou acréscimo entre os momentos pré e pós apenas no grupo GTFS (P:0,004). Entretanto, a análise dos resultados do RQ não demonstrou diferenças nos três grupos. (Tabela 5).

Tabela 5 - Análise comparativa entre os momentos Pré x Pós do Pulso $\mathrm{O}_{2}$ e RQ

\begin{tabular}{|c|c|c|c|c|c|c|}
\hline VARIÁVEL & $\begin{array}{c}\text { GTFS } \\
(\text { Média } \pm D P)\end{array}$ & $\begin{array}{c}\text { GTFNS } \\
(\text { Média } \pm \text { DP) }\end{array}$ & $\begin{array}{c}\text { GC } \\
(\text { Média } \pm \text { DP) }\end{array}$ & $\begin{array}{c}P \\
\text { GTFS } \\
\text { vs } \\
\text { GTFNS }\end{array}$ & $\begin{array}{c}P \\
\text { GTFS } \\
\text { vs } \\
\text { GC }\end{array}$ & $\begin{array}{c}P \\
\text { GTFNS } \\
\text { vs } \\
\text { GC }\end{array}$ \\
\hline \multicolumn{7}{|c|}{ Pulso $\mathrm{O}_{2}$ CFM - ml/bpm } \\
\hline Pré & $12,91 \pm 3,83$ & $12,09 \pm 2,50$ & $10,79 \pm 2,79$ & \multirow{3}{*}{0,059} & \multirow{3}{*}{0,059} & \multirow{3}{*}{0,059} \\
\hline Pós & $14,25 \pm 3,73$ & $12,16 \pm 2,76$ & $11,09 \pm 2,50$ & & & \\
\hline$p$ & 0,01 & 0,87 & 0,78 & & & \\
\hline \multicolumn{7}{|l|}{ RQ CFM } \\
\hline Pré & $1,14 \pm 0,10$ & $1,14 \pm 0,11$ & $1,14 \pm 0,07$ & \multirow{3}{*}{0,829} & \multirow{3}{*}{0,829} & \multirow{3}{*}{0,829} \\
\hline Pós & $1,18 \pm 0,11$ & $1,15 \pm 0,11$ & $1,14 \pm 0,06$ & & & \\
\hline$p$ & 0,23 & 0,23 & 0,23 & & & \\
\hline
\end{tabular}

Legendas: CFM - Capacidade Funcional Máxima; DP - Desvio padrão. 


\section{Frequência cardíaca}

A análise comparativa dos resultados da $\mathrm{FC}_{\text {máx }}$ e do percentual da $\mathrm{FC}_{\text {máx }}$ predita entre os momentos pré e pós não demonstrou diferenças nos três grupos (Tabela 6).

Tabela 6 - Análise comparativa entre os momentos Pré x Pós da FCmax e \% da FC Predita

\begin{tabular}{|c|c|c|c|c|c|c|}
\hline VARIÁVEL & $\begin{array}{c}\text { GTFS } \\
\text { (Média } \pm \text { DP) }\end{array}$ & $\begin{array}{c}\text { GTFNS } \\
(\text { Média } \pm D P)\end{array}$ & $\begin{array}{c}\text { GC } \\
(\text { Média } \pm D P)\end{array}$ & $\begin{array}{c}P \\
\text { GTFS } \\
\text { vs } \\
\text { GTFNS }\end{array}$ & $\begin{array}{c}P \\
\text { GTFS } \\
\text { vs } \\
\text { GC }\end{array}$ & $\begin{array}{c}P \\
\text { GTFNS } \\
\text { vs } \\
\text { GC }\end{array}$ \\
\hline \multicolumn{7}{|c|}{ FCmáx obtida - bpm } \\
\hline Pré & $150,64 \pm 14,25$ & $150,71 \pm 15,01$ & $153,25 \pm 18,36$ & \multirow{3}{*}{0,953} & \multirow{3}{*}{0,953} & \multirow{3}{*}{0,953} \\
\hline Pós & $150,43 \pm 13,66$ & $153,47 \pm 19,30$ & $150,81 \pm 16,57$ & & & \\
\hline$p$ & 0,98 & 0,98 & 0,98 & & & \\
\hline \multicolumn{7}{|l|}{ \%da FC predita } \\
\hline Pré & $92,65 \pm 10,52$ & $93,78 \pm 12,30$ & $92,80 \pm 12,77$ & \multirow{2}{*}{0,975} & \multirow{2}{*}{0,975} & \multirow{2}{*}{0,975} \\
\hline Pós & $92,80 \pm 9,87$ & $153,47 \pm 19,30$ & $92,28 \pm 10,30$ & & & \\
\hline$p$ & 0,77 & 0,77 & 0,77 & & & \\
\hline
\end{tabular}

Legendas: FC - Frquência Cardíaca; DP - Desvio padrão.

\subsubsection{Qualidade de Vida}

A análise comparativa dos achados da QdV demonstrou que no GTFS ocorreu aumento significativo entre o momento pré e pós treinamento físico, em relação aos domínios dor no corpo, saúde geral e sumário de saúde física do SF-36. No grupo GTFNS, entretanto, ocorreu melhora apenas no domínio função social do SF-36 e escala de desconforto torácico no Aquarel, e no GC a melhora ocorreu apenas em relação ao domínio escala de dispneia (Aquarel). (Tabela 7).

Considerando toda a casuística, a análise comparativa dos achados de QdV nos momentos pré e pós não demonstrou diferenças estatísticas. 
Tabela 7 - Análise comparativa da QdV Pré x Pós, em cada grupo

\begin{tabular}{|c|c|c|c|c|c|c|c|c|c|}
\hline \multirow[b]{2}{*}{ Domínio } & \multicolumn{3}{|c|}{ GTFS } & \multicolumn{3}{|c|}{ GTFNS } & \multicolumn{3}{|c|}{ GC } \\
\hline & $\begin{array}{c}\text { Pré } \\
\text { Média } \pm \text { DP }\end{array}$ & $\begin{array}{c}\text { Pós } \\
\text { Média } \pm \text { DP }\end{array}$ & $\mathbf{P}$ & $\begin{array}{c}\text { Pré } \\
\text { Média } \pm \text { DP }\end{array}$ & $\begin{array}{c}\text { Pós } \\
\text { Média } \pm \text { DP }\end{array}$ & $\mathbf{P}$ & $\begin{array}{c}\text { Pré } \\
\text { Média } \pm \text { DP }\end{array}$ & $\begin{array}{c}\text { Pós } \\
\text { Média } \pm \text { DP }\end{array}$ & $\mathbf{P}$ \\
\hline Capacidade funcional & $85,28 \pm 16,32$ & $84,29 \pm 16,32$ & 0,69 & $82,78 \pm 23,59$ & $79,44 \pm 24,36$ & 0,12 & $74,41 \pm 23,90$ & $74,31 \pm 23,60$ & 0,53 \\
\hline Aspectos físicos & $53,57 \pm 40,26$ & $67,86 \pm 45,39$ & 0,05 & $68,06 \pm 40,04$ & $72,22 \pm 43,63$ & 0,5 & $70,59 \pm 39,76$ & $64,71 \pm 41,51$ & 0,51 \\
\hline Dor & $71,07 \pm 31,43$ & $87,68 \pm 15,11$ & 0,03 & $82,64 \pm 15,75$ & $78,75 \pm 21,73$ & 0,4 & $78,82 \pm 23,52$ & $76,47 \pm 25,80$ & 0,72 \\
\hline Saúde geral & $70,71 \pm 17,74$ & $80,36 \pm 13,51$ & 0,04 & $75,83 \pm 23,27$ & $73,33 \pm 19,92$ & 0,34 & $73,82 \pm 11,39$ & $72,06 \pm 21,72$ & 1,00 \\
\hline Vitalidade & $78,57 \pm 18,23$ & $78,93 \pm 17,34$ & 0,93 & $71,94 \pm 20,15$ & $68,61 \pm 19,00$ & 0,53 & $65,59 \pm 24,74$ & $71,47 \pm 20,44$ & 0,27 \\
\hline Aspectos sociais & $90,18 \pm 19,10$ & $97,32 \pm 10,02$ & 0,07 & $84,03 \pm 22,60$ & $93,06 \pm 16,16$ & 0,04 & $91,91 \pm 17,64$ & $94,12 \pm 10,93$ & 0,78 \\
\hline Aspectos emocionais & $52,38 \pm 46,61$ & $69,05 \pm 46,15$ & 0,10 & $66,67 \pm 45,73$ & $70,37 \pm 44,11$ & 0,58 & $72,55 \pm 42,87$ & $72,55 \pm 41,22$ & 0,92 \\
\hline Saúde mental & $74,29 \pm 21,72$ & $79,14 \pm 18,44$ & 0,14 & $70,17 \pm 19,06$ & $70,22 \pm 14,85$ & 0,75 & $70,35 \pm 18,38$ & $73,65 \pm 16,91$ & 0,45 \\
\hline Sumário saúde física & $70,16 \pm 18,58$ & $80,05 \pm 15,77$ & 0,02 & $77,33 \pm 20,66$ & $75,93 \pm 21,82$ & 0,86 & $74,41 \pm 19,19$ & $71,89 \pm 20,07$ & 0,53 \\
\hline Sumário saúde mental & $73,86 \pm 21,01$ & $81,11 \pm 15,67$ & 0,07 & $73,2 \pm 21,43$ & $75,57 \pm 18,67$ & 0,59 & $75,1 \pm 21,42$ & $77,95 \pm 14,70$ & 0,64 \\
\hline Desconforto no peito & $91,74 \pm 14,89$ & $95,31 \pm 10,38$ & 0,14 & $93,75 \pm 7,57$ & $96,53 \pm 6,32$ & 0,04 & $95,77 \pm 9,03$ & $95,77 \pm 9,17$ & 1,00 \\
\hline Dispneia & $88,27 \pm 15,37$ & $88,52 \pm 8,54$ & 0,84 & $85,91 \pm 17,55$ & $91,67 \pm 13,36$ & 0,12 & $85,72 \pm 18,25$ & $93,28 \pm 8,07$ & 0,02 \\
\hline Arritmias & $87,68 \pm 15,58$ & $92,5 \pm 7,27$ & 0,16 & $87,15 \pm 12,58$ & $88,33 \pm 13,61$ & 0,68 & $95,29 \pm 6,24$ & $95 \pm 8,47$ & 0,93 \\
\hline
\end{tabular}

Legendas: QdV - Qualidade de Vida; DP - Desvio padrão. 


\subsubsection{Análises de Correlação}

Considerando toda a casuística, no momento pré-treinamento, a análise de correlação entre o $\mathrm{VO}_{2 \text { pico }}$ à $\mathrm{CFM}$ e $\mathrm{QdV}$ demonstrou significância em relação aos domínios capacidade funcional, aspectos físicos, aspectos emocionais e sumário de saúde física do questionário SF-36. A análise no momento pós-treinamento, entretanto, revelou correlação positiva apenas no domínio capacidade funcional do SF-36 (Tabela 8).

Tabela 8 - Análise da correlação entre os domínios da QdV e $\mathrm{VO}_{2 \text { pico }}$

\begin{tabular}{|c|c|c|c|c|}
\hline \multirow{2}{*}{ DOMÍNIOS } & \multicolumn{2}{|c|}{ PRÉ } & \multicolumn{2}{|c|}{ PÓS } \\
\hline & $r$ & $p$ & $\mathbf{r}$ & $p$ \\
\hline Capacidade funcional & 0,36 & $<0,01$ & 0,28 & 0,04 \\
\hline Aspectos físicos & 0,33 & 0,01 & 0,05 & 0,70 \\
\hline Dor & 0,14 & 0,27 & 0,08 & 0,58 \\
\hline Saúde Geral & 0,19 & 0,15 & 0,19 & 0,15 \\
\hline Vitalidade & 0,07 & 0,55 & 0,04 & 0,75 \\
\hline Aspectos sociais & 0,11 & 0,38 & 0,10 & 0,46 \\
\hline Aspectos emocionais & 0,26 & 0,04 & 0,21 & 0,13 \\
\hline Saúde mental & 0,14 & 0,27 & 0,03 & 0,82 \\
\hline Sumário saúde física & 0,36 & $<0,01$ & 0,16 & 0,25 \\
\hline Sumário saúde mental & 0,20 & 0,12 & 0,14 & 0,33 \\
\hline Desconforto no peito & 0,05 & 0,69 & 0,22 & 0,11 \\
\hline Dispneia & 0,10 & 0,43 & 0,12 & 0,39 \\
\hline Arritmias & 0,07 & 0,56 & 0,15 & 0,29 \\
\hline
\end{tabular}


5 Discussão 


\section{DISCUSSÃO}

O principal achado deste estudo, incremento de $\mathrm{VO}_{2}$ pico por volta de $12 \%$ em portadores de MCD submetidos ao treinamento supervisionado, não foi objeto de estudos prévios e tem muita relevância porque reflete melhora expressiva de capacidade aeróbia em uma população habitualmente limitada.

Sabe-se que o $\mathrm{VO}_{2 \text { pico }}$ possui alguns fatores limitantes como sistema pulmonar, o desempenho cardíaco, as limitações da musculatura esquelética, a capacidade de transporte de $\mathrm{O}_{2}$ pelo complexo oxi-hemoglobina, gradientes de difusão do $\mathrm{O}_{2}$ periférico, níveis de enzimas mitocondriais nas fibras musculares e densidade capilar, entre outros ${ }^{51}$.

Ganhos típicos de $\mathrm{VO}_{2 \text { pico }}$ por endurance, em não portadores de $\mathrm{MCD}$, após 3 meses de treinamento variam entre $3 \%$ e $20 \%$; ganhos acima desses valores associam-se a características genéticas favoráveis e a treinamentos em indivíduos com $\mathrm{VO}_{2 \text { pico }}$ inicialmente abaixo da média ${ }^{24,28}$. Esse princípio é válido tanto para indivíduos sadios como para indivíduos com doenças cardiovasculares, nos quais benefícios ótimos ocorrem sob programas de treinamento que privilegiam necessidades individuais e fatores genéticos. Nunes et al. ${ }^{52}$ demonstraram um crescimento significante de $5 \%$ do $\mathrm{VO}_{2 \text { máx }}$ em 3 meses de treinamento físico aeróbico em atletas de voleibol. Esses atletas partiram de um relevante $\mathrm{VO}_{2 \text { máx }}$ basal (média de 48,6 ml/Kg/min).

Em portadores de $\mathrm{MCD}$, Lenke et al. ${ }^{49}$ compararam o $\mathrm{VO}_{2 \text { máx }}$, carga de trabalho e FC no LA, pré e pós implante, e observou aumento significativo (16\% a $25 \%$ ) de todos esses parâmetros, utilizando programação responsiva em frequência. $\mathrm{Na}$ mesma linha de pesquisa, Sharp et al. ${ }^{42}$ demonstraram vantagens do uso de sensores de atividade física para modulação de frequência cardíaca em pacientes portadores de $\mathrm{MCD}$, assim como o tipo ideal de sensor a ser utilizado em cada patologia de base. Devido ao fato de nossos pacientes NÃO serem portadores de disfunção ventricular, ao contrário dos estudos de Lenke, e apresentarem reposta 
cronotrópica normal, optamos por mantê-los durante o protocolo com o sensor de resposta desativado.

Em pacientes com IC e MCD, RC ou CDI, o estudo HF-ACTION ${ }^{53}$ avaliou os efeitos do treinamento físico. Foram randomizados 2.331 pacientes com ICC, CF, NYHA II-IV e FEVE $\leq 35 \%$, avaliados no início e 3 meses pós-treinamento físico, agrupados em: Grupo 1 sem dispositivos, Grupo 2 com MCD ou CDI estimulando a ponta de VD e Grupo 3 com RC (associado ou não ao CDI). No grupo 1 ocorreu redução do $\mathrm{VO}_{2 \text { máx }}$ e do tempo do exercício. No grupo 2 ocorreu aumento de 4\% no $\mathrm{VO}_{2 \text { pico }}$ e, no grupo 3, aumento do $\mathrm{VO}_{2 \text { pico }}$ de $7 \%$.

Nossos pacientes não eram portadores de ICC, e o treinamento físico supervisionado promoveu incremento considerável do $\mathrm{VO}_{2 \text { máx }}$ provavelmente por recondicionamento do sistema cardiopulmonar, tornando-os mais adaptados à prática de atividade física. Apesar de recomendações das diretrizes defendendo exercício, existem poucos dados longitudinais desta prática assim como dos resultados posteriores em pacientes portadores de MCD ou outros dispositivos de ritmo cardíacos implantados, nem tampouco sobre o impacto da estimulação de VD comparado à estimulação biventricular ${ }^{53}$. Sendo necessário, entretanto, avaliação clínica específica, seguida da realização de ACE, além de ajuste dos parâmetros programáveis da estimulação cardíaca para uma correta prescrição individualizada.

Com relação aos achados de QdV, nosso estudo observou correlações estatísticas, embora fracas, entre $\mathrm{VO}_{2 \text { máx }}$ e algumas das dimensões do SF36. Nenhuma correlação foi observada em relação às dimensões do questionário Aquarel. A dimensão capacidade funcional foi o domínio do SF36 que se correlacionou com maior número de condições e grupamentos, coerentemente no pré e pós estudo e ao considerar todos os participantes da pesquisa (sem divisão por grupo) nos momentos pré e pós estudo.

Poucos estudos avaliaram correlações entre QdV com outras variáveis clínico epidemiológica em portadores de $\mathrm{MCD}^{44,46}$. Gomes et al. ${ }^{45}$, avaliando pacientes submetidos à TRC, não demonstrou correlação entre os domínios de QdV do questionário Aquarel em relação a idade, sexo, escolaridade, ocupação e renda individual. 
As análises de correlação entre o $\mathrm{VO}_{2 \text { máx }}$ e os domínios dos questionários de QdV encontrados neste e em outros trabalhos da literatura ainda não conseguiram estabelecer padrão de correlações entre a capacidade funcional avaliada pelo $\mathrm{VO}_{2 \text { pico }}$ e os questionários de $\mathrm{QdV}^{*}$. Nessa linha, Cunha et al. ${ }^{43}$ procuraram correlacionar a classe funcional de insuficiência cardíaca (CFIC) com a $\mathrm{QdV}$, segundo os questionários SF-36 e Aquarel. Neste estudo mostrou-se que a CFIC se correlacionou inversamente e significativamente com os domínios de capacidade funcional, dor no corpo e vitalidade, bem como entre idade e os domínios aspecto emocional e capacidade funcional do SF-36.

Apesar de nosso estudo ter registrado variações de alguns domínios dos questionários de $\mathrm{QdV}$ entre os momentos pré e pós treinamento em todos os grupos, não houve um padrão de comportamento entre estas variações. De fato, não esperávamos variações expressivas na QdV ao logo do tempo.

A maioria dos estudos sobre o tema compara a QdV nos momentos pré implante e 6 a 24 meses após. Num sub-estudo do FOLLOWPACE ${ }^{54}$, observou-se melhora da QdV em todas as dimensões do SF-36 após 1 ano de implante, seguido, entretanto, de gradual declínio no segundo e terceiro ano pós-implante. Em relação ao Aquarel houve padrão semelhante, com melhora em todos os domínios no primeiro ano pós-implante, principalmente na dimensão de arritmia, mantendo-se estável por 5 anos, quando então inicia piora gradual. A população de nosso estudo, em média, tem 50 meses de implante de MPD, o que representa afastamento da fase em que mais se relata melhora de QdV, o pós-implante imediato. Além disso, esses questionários foram aplicados, em nosso estudo, em intervalos de apenas 4 meses, enquanto na maioria dos estudos isso ocorreu no intervalo mínimo de 6 meses. Mesmo assim, observou-se melhora da QdV no GTFS, em alguns domínios do questionário SF-36.

O estudo COMBAT ${ }^{55}$ revelou a superioridade da estimulação átriobiventricular sobre a convencional, em relação à QdV, CFIC, FEVE e volume sistólico final. No entanto, praticamente não demonstrou variação da QdV na manutenção do mesmo modo de estimulação. O COMBAT deixou claro que uma estimulação cardíaca mais fisiológica é capaz de promover melhora significativa da 
$\mathrm{QdV}$, corroborando nossa premissa de que pacientes em programa de treinamento físico supervisionado e com FEVE normal não teriam ganho perceptível de QdV, além do ocorrido entre o pré e pós-operatório imediato de implante de MCD. Entretanto, o que se observou no estudo COMBAT é que o ganho perceptível em QdV não foi acompanhado de ganho significativo de $\mathrm{VO}_{2 \text { máx }}$ demonstrando, assim, como no nosso estudo, que melhora da CFM não é, necessariamente, acompanhada de melhora da QdV.

É importante esclarecer o conceito generalizado e muito difundido de que a estimulação responsiva em frequência está fortemente associada à melhora de qualidade de vida. Esse conceito foi gerado a partir da publicação do estudo MOST (Mode Selection Trial in Sinus Node Dysfunction) ${ }^{21}$ que demonstrou melhora da QdV em pacientes com disfunção sinusal sob estimulação dupla-câmara (modo DDD) em relação à estimulação câmara única ventricular responsivo em frequência (modo VVIR). Esse comportamento, entretanto, não foi observado em pacientes com Bloqueio Atrio-Ventricular (BAV), demonstrando que a presença de sensor de resposta em frequência ativado apenas tem impacto sobre QdV na presença de disfunção sinusal. Esses achados do estudo MOST não valem para o nosso estudo no qual, evidentemente, o modo responsivo não foi ativado, porque foram incluídos apenas pacientes com BAV e função sinusal normal.

Para finalizar, deve-se destacar a importância da aderência do portador de MCD a um programa de treinamento físico específico, essencial na contribuição da melhora da capacidade funcional obtida em nosso estudo. Isso porque esses ganhos foram associados ao caráter da supervisão aplicada ao grupo beneficiado com o treinamento, no qual a taxa de aderência foi claramente elevada. Este comportamento também foi demonstrado por Belardinelli et al. ${ }^{56}$ em pacientes com insuficiência cardíaca, que observaram incremento de $\mathrm{VO}_{2 \text { pico }}$ no LA apenas nos pacientes sob treinamento físico supervisionado.

Como corolário das considerações feitas a respeito dos achados de nosso estudo, projetamos impacto clínico muito positivo, em longo prazo, aos portadores de $\mathrm{MCD}$, em caso de manutenção da aderência a um programa de treinamento físico supervisionado. Neste sentido, o Comitê de Reabilitação e Prevenção da American 
Heart Association ${ }^{57}$ relatou recentemente redução de mortalidade e morbidade de 25\% atribuída à aplicação dos programas de reabilitação cardiovascular, considerando a importância da aderência e a ainda necessidade de melhora de suas taxas, sobretudo para populações de baixo poder econômico, e idade avançada, como fator de melhores resultados clínicos. 
6 Conclusões 


\section{CONCLUSÕES}

Em portadores de MCD sem disfunção ventricular, o treinamento físico protocolar supervisionado:

1- proporciona melhora expressiva do consumo de oxigênio e de suas repercussões funcionais, independentemente da terapêutica medicamentosa e das características clínico-epidemiológicas.

2- melhora a qualidade de vida, medida pelos questionários SF-36 e Aquarel, considerando os domínios dor no corpo, saúde geral e sumário da saúde física.

Por outro lado, o treinamento físico protocolar não-supervisionado não proporcionou qualquer melhora funcional. 
7 Anexos 


\title{
Anexo A - Termo de Consentimento Livre e Esclarecido
}

\author{
HOSPITAL DAS CLÍNICAS DA FACULDADE DE MEDICINA DA \\ UNIVERSIDADE DE SÃO PAULO-HCFMUSP
}

TERMO DE CONSENTIMENTO LIVRE E ESCLARECIDO

\section{DADOS DE IDENTIFICAÇÃO DO SUJEITO DA PESQUISA OU RESPONSÁVEL LEGAL}

1. NOME:

DOCUMENTO DE IDENTIDADE $\mathrm{N}^{\circ}$ : .$M \square \mathrm{F} \square$ DATA NASCIMENTO: ....................... ENDEREÇO $\mathrm{N}^{\mathrm{o}}$ APTO:

BAIRRO: CIDADE

CEP: TELEFONE: DDD ( .)

2.RESPONSÁVEL LEGAL

NATUREZA (grau de parentesco, tutor, curador etc.)

DOCUMENTO DE IDENTIDADE : SEXO: $\mathrm{M} \square \mathrm{F} \square$ DATA NASCIMENTO.: ENDEREÇO: $\mathrm{N}^{\mathrm{o}}$ APTO:

BAIRRO: CEP: TELEFONE: DDD CIDADE:

\section{DADOS SOBRE A PESQUISA}

1. TÍTULO DO PROTOCOLO DE PESQUISA

Efeito do Treinamento Físico em Portadores de Marcapasso

2. PESQUISADOR : Dr. Martino Martinelli Filho

CARGO/FUNÇÃO: Médico Chefe da Unidade Clínica de Arritmia e Marcapasso - InCorHC/FMUSP

INSCRIÇÃO CONSELHO REGIONAL No 27133

UNIDADE DO HCFMUSP: Unidade Clínica de Arritmia e Marcapasso - InCorHC/FMUSP

3. AVALIAÇÃO DO RISCO DA PESQUISA

$\begin{array}{llll}\text { RISCO MÍNIMO } & \square & \text { RISCO MÉDIO } & \mathrm{x} \\ \text { RISCO BAIXO } & \square & \text { RISCO MAIOR } & \square\end{array}$

4. DURAÇÃO DA PESQUISA : 18 meses 


\section{HOSPITAL DAS CLÍNICAS DA FACULDADE DE MEDICINA DA UNIVERSIDADE DE SÃO PAULO-HCFMUSP}

\section{1 - Justificativa e os objetivos da pesquisa:}

Frequentemente os portadores de marcapasso evitam atividades que envolvam algum grau de esforço físico. Na maioria das vezes isso é causado mais pelo medo e apreensão do próprio paciente, por se considerar portador de uma doença cardíaca e eventualmente acabar passando mal durante o exercício. O implante de marcapasso em muitos pacientes não causa nenhuma limitação a diversos tipos de atividade física. Os benefícios da atividade física já foram comprovados tanto para a prevenção quanto para o tratamento de várias doenças, principalmente as cardíacas. Acreditamos que tais benefícios possam estar presentes também para portadores de marcapasso, melhorando qualidade de vida e capacidade física. Sua presença é muito importante pois, assim, poderemos saber se os pacientes com marcapasso, depois do treinamento físico, conseguiram melhorias na sua condição física que o deixam próximo de pessoas sem marcapasso.

\section{2 - Procedimentos que serão utilizados e propósitos, incluindo a identificação dos procedimentos que são experimentais:}

Avaliação de qualidade de vida. Neste questionário você será questionado sobre sua vida e como está se sentindo com relação a sua saúde.

Exame de Exercício na Esteira. Você será então submetido a um exame de esforço físico, denominado de teste ergoespirométrico, que consiste em caminhar numa estereira rolante e que se presta para avaliar a sua capacidade máxima de realizar exercício físico. Nesse exame, serão colocados adesivos no seu peito para que possamos acompanhar os batimentos do seu coração. Também mediremos sua pressão a cada 2 minutos durante o exame. Na sua boca será colocado um aparelho para que possamos analisar a sua respiração durante o período de esforço físico. Esse exame tem o objetivo de avaliar a sua capacidade máxima de fazer exercício. Ele também serve para saber como está o seu estado de saúde. Ele será feito por um médico que tem muita experiência e realiza esse tipo de exame várias vezes ao dia.

Programa de Exercício. Caso você seja sorteado para o grupo que fará exercício aqui no nosso laboratório, você realizará o exercício em esteira rolante por 40 minutos, 3 vezes por semana na unidade de reabilitação do Incor, por um período de 4 meses. Esse programa de exercício será ministrado por um professor de educação física especializado e supervisionado por um médico cardiologista. No final desse programa de exercício, você fará todos os exames de novo para verificar se a sua doença do coração melhorou com o programa de exercício. Caso você faça parte do grupo que terá acompanhamento médico, mas fará exercício fora do ambiente hospitalar, ou seja, você realizará caminhada por 40 minutos, 3 vezes por semana, em uma praça, na rua ou algum lugar próximo a sua casa, por um período de 4 meses e repetirá os exames após este período. O grupo que não fará treinamento (grupo controle) terá acompanhamento médico e realizará os exames na entrada do protocolo e após 4 meses para compararmos os resultados do seus exames com o grupo de pacientes que fez exercício físico.

\section{3 - Desconfortos e riscos esperados}

Exame de Exercício na Esteira. O exercício que você fará na esteira rolante vai fazer o seu coração bater bastante rápido e vai causar cansaço, mas tudo isto passará em alguns minutos após o fim do exercício. É muito difícil de acontecer, mas o exercício pode provocar batimentos irregulares no seu coração e até uma parada no seu coração. Se isto acontecer, você será imediatamente socorrido pelo médico cardiologista, muito experiente, que estará 
fazendo o exame em você. Esse exame de esteira é feito todos os dias na Unidade de Reabilitação Cardiovascular e Fisiologia do Exercício aqui no InCor. Portanto, você não deve se preocupar com isso, porque o médico estará controlando todas as reações do seu coração.

Programa de Exercício. No começo do programa de exercício físico, você poderá sentir um pouco de cansaço, mas isto logo passará, porque você vai se acostumar com ele. O risco de acontecer alguma coisa com você durante o programa de exercício é muito pequeno, porque você fará exercício numa intensidade moderada, isto é, bem inferior àquela que você fez no teste de esteira. Caso você sinta alguma coisa, o médico que supervisiona o programa lhe atenderá imediatamente.

\section{4 - Benefícios que poderão ser obtidos:}

Esta pesquisa irá nos ajudar a saber se o exercício melhora a qualidade de vida e a capacidade física de pacientes que possuem marcapasso cardíaco. Caso você seja sorteado para participar do grupo de exercício supervisionado, você deverá ter benefícios com o programa de exercícios e ainda ser acompanhado por nossa equipe especializada, já que estudos do nosso grupo e de outros grupos no mundo têm verificado que o exercício físico feito regularmente melhora muito a disposição, a condição física e a saúde das pessoas que têm doença do coração. Caso você seja sorteado para o grupo que não fará exercício no nosso laboratório também poderá ter benefícios, mas não serão acompanhados durante os dias do exercício e sim no final de cada mês onde faremos o acompanhamento do seu treino e acompanhamento médico.

\section{5 - Procedimentos alternativos que possam ser vantajosos para o indivíduo:}

Neste momento, não há procedimentos alternativos.

\section{6 - Garantia de acesso:}

- $\mathrm{O} \operatorname{Sr}(\mathrm{a})$ terá acesso, a qualquer momento, em qualquer etapa do estudo, às informações sobre procedimentos, riscos e benefícios relacionados à pesquisa, inclusive para esclarecer eventuais dúvidas.

- O principal investigador é o Dr. Martino Martinelli Filho que pode ser encontrado no endereço Av. Dr. Enéas de Carvalho Aguiar, 44, AB - telefone: 3069 - 5516;

- Você também poderá esclarecer suas dúvidas com o Dr. Iury Baretta Av. Dr. Enéas de Carvalho Aguiar, 44 - AB - telefone: 3069 - 5516 e Thaís S. Nobre P. Santos Av. Dr. Enéas de Carvalho Aguiar, 44 - $1^{\circ}$ subsolo, B1 2 - telefone: 3069 - 5043;

- Se você tiver alguma consideração ou dúvida sobre a ética da pesquisa, entre em contato com o Comitê de Ética em Pesquisa (CEP) - Rua Ovídio Pires de Campos, $225-5^{\circ}$ andar - tel: 3069-6442 ramais 16, 17, 18 ou 20, FAX: 3069-6442 ramal 26

- E-mail: cappesq@hcnet.usp.br; 
- É garantido a você a liberdade de retirar o consentimento a qualquer momento e deixar de participar do estudo, sem qualquer prejuízo à continuidade de seu tratamento na Instituição;

- As informações obtidas serão analisadas em conjunto com outros pacientes, não sendo divulgada a identificação de nenhum paciente;

- O Sr (a) terá direito de ser mantido atualizado sobre os resultados parciais das pesquisas, quando em estudos abertos, ou de resultados que sejam do conhecimento dos pesquisadores;

- Não há despesas pessoais para o participante em qualquer fase do estudo, incluindo exames e consultas. Também não há compensação financeira relacionada à sua participação. Se existir qualquer despesa adicional, ela será absorvida pelo orçamento da pesquisa. O pesquisador utilizará os dados e o material coletado somente para esta pesquisa.

Acredito ter sido suficientemente informado a respeito das informações que li ou que foram lidas para mim, descrevendo o estudo "Efeitos do Treinamento Físico em Portadores de Marcapasso". 


\section{HOSPITAL DAS CLÍNICAS DA FACULDADE DE MEDICINA DA UNIVERSIDADE DE SÃO PAULO-HCFMUSP}

Eu discuti com o Dr. Martino Martinelli Filho sobre a minha decisão em participar nesse estudo. Ficaram claros para mim quais são os propósitos do estudo, os procedimentos a serem realizados, seus desconfortos e riscos, as garantias de confidencialidade e de esclarecimentos permanentes. Ficou claro também que minha participação é isenta de despesas e que tenho garantia do acesso a tratamento hospitalar quando necessário. Concordo voluntariamente em participar deste estudo e poderei retirar o meu consentimento a qualquer momento, antes ou durante o mesmo, sem penalidades ou prejuízo ou perda de qualquer benefício que eu possa ter adquirido, ou no meu atendimento neste Serviço.

Assinatura do paciente/representante legal

Data

Data

Assinatura da testemunha

Data

para casos de pacientes menores de 18 anos, analfabetos, semi-analfabetos ou portadores de deficiência auditiva ou visual.

\section{(Somente para o responsável do projeto)}

Declaro que obtive de forma apropriada e voluntária o Consentimento Livre e Esclarecido deste paciente ou representante legal para a participação neste estudo.

Data

$1 /$




\section{INSTRUÇÕES PARA PREENCHIMENTO \\ (Resolução Conselho Nacional de Saúde 196, de 10 outubro 1996)}

1. Este termo conterá o registro das informações que o pesquisador fornecerá ao sujeito da pesquisa, em linguagem clara e accessível, evitando-se vocábulos técnicos não compatíveis com o grau de conhecimento do interlocutor.

2. A avaliação do grau de risco deve ser minuciosa, levando em conta qualquer possibilidade de intervenção e de dano à integridade física do sujeito da pesquisa.

3. O formulário poderá ser preenchido em letra de forma legível, datilografia ou meios eletrônicos.

4. Este termo deverá ser elaborado em duas vias, ficando uma via em poder do paciente ou seu representante legal e outra deverá ser juntada ao prontuário do paciente.

5. A via do Termo de Consentimento Pós-Informação submetida à análise da Comissão de Ética para Análise de Projetos de Pesquisa - CAPPesq deverá ser idêntica àquela que será fornecida ao sujeito da pesquisa. 


\section{Anexo B - Figura}

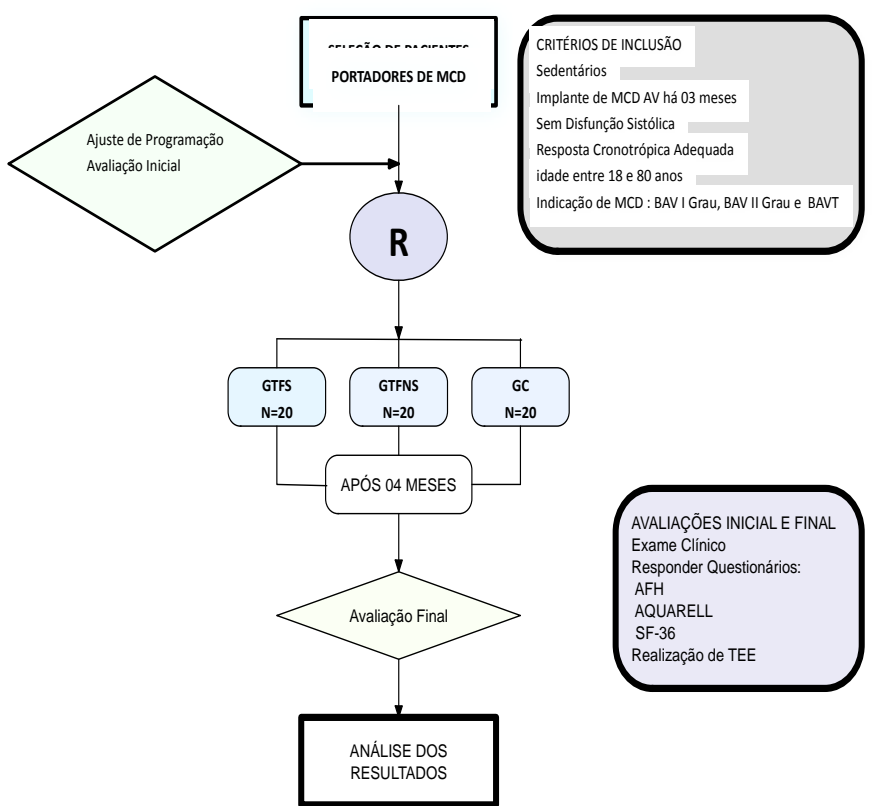

Figura 1 - Desenho do Estudo 
7 Referências 


\section{REFERÊNCIAS}

1 Thompson PD, Buchner D, Pina IL, Williams MA, Marcus BH, Berra K, et al.; American Heart Association Council on Clinical Cardiology Subcommittee on Exercise, Rehabilitation, and Prevention; American Heart Association Council on Nutrition, Physical Activity, and Metabolism Subcommittee on Physical Activity. Exercise and physical activity in the prevention and treatment of atherosclerotic cardiovascular disease: a statement from the Council on Clinical Cardiology (Subcommittee on Exercise, Rehabilitation, and Prevention) and the Council on Nutrition, Physical Activity, and Metabolism (Subcommittee on Physical Activity). Circulation. 2003;107(24):3109-16.

2 Pollock ML, Gaesser GA, Butcher JD, Després J-P, Dishman RK, Franklin BA, Garber CE. American College of Sports Medicine Position Stand: the recommended quantity and quality of exercise for developing and maintaining cardio- respiratory and muscular fitness and flexibility in healthy adults. Med Sci Sports Exerc. 1998;30(6):975-91.

3 Biotronik. O que você precisa saber sobre o seu marcapasso. 2011. Disponível em: http://www.biotronik.com/files/2F7D818D75D6E09EC1257A1600366B11/ \$FILE/Patientbrochure_IPG_PT.pdf. Acesso em: 14 jun. 2006.

4 Salgado C. Tratado de estimulação cardíaca artificial. 5ª ed. Barueri: Manole; 2015.

5 Ellenbogen KA, Kaszala K. Cardiac pacing and ICDs. Revisado da NASPE (North American Society of Pacing and Electrophysiology) e BPEG (British Pacing and Electrophysiology Group). 6 ${ }^{\text {a }}$ ed. Hoboken, NJ: Wiley, Blackwell; 2014.

6 Hansen JT. Netter-Anatomia Clínica. Rio de Janeiro: Elsevier Brasil; 2015.

7 Martinelli M, Siqueira SF. Atlas de marca-passo - a função através do eletrocardiograma. 2a ed. São Paulo: Atheneu; 2012. 
8 Pluim BM, Zwinderman AH, van der Laarse A, van der Wall EE. The athlete's heart. A meta-analysis of cardiac structure and function. Circulation. 2000;101(3):336-44.

9 Dorn GW 2nd. The fuzzy logic of physiological cardiac hypertrophy. Hypertension. 2007;49(5):962-70.

10 Steding K, Engblom H, Buhre T, Carlsson M, Mosén H, Wohlfart B, Arheden H. Relation between cardiac dimensions and peak oxygen uptake. [Abstract]. J Cardiovasc Magn Reson. 2010;12:8.

11 McCarthy JP, Agre JC, Graf BK, Pozniak MA, Vailas AC. Compatibility of adaptive responses with combining strength and endurance training. Med Sci Sports Exerc. 1995;27(3):429-36.

12 Williams MA, Haskell WL, Ades PA, Amsterdam EA, Bittner V, Franklin BA, Gulanick M, Laing ST, Kerry J. Stewart KJ; American Heart Association Council on Clinical Cardiology; American Heart Association Council on Nutrition, Physical Activity, and Metabolism. Resistance exercise in individuals with and without cardiovascular disease: 2007 update: a scientific statement from the American Heart Association Council on Clinical Cardiology and Council on Nutrition, Physical Activity, and Metabolism. Circulation. 2007;116(5):572-84.

13 Hashimoto NY, Fernandes T, Soci UPR, Oliveira EM. Molecular determinants of cardiac hypertrophy induced by different amounts of aerobic exercise training. Rev Bras Cardiol. 2011;24(3):153-62.

14 Pelliccia A, Kinoshita N, Pisicchio C, Quattrini F, DiPaolo FM, Ciardo R, Di Giacinto B, Guerra E, De Blasiis E, Casasco M, Culasso F, Maron BJ. Long-term clinical consequences of intense, uninterrupted endurance training in olympic athletes. J Am Coll Cardiol. 2010;55(15):1619-25.

15 La Gerche A, Prior DL, Heidbüchel H. Clinical consequences of intense endurance exercise must include assessment of the righ ventricle. J Am Coll Cardiol. 2010; 56(15):1263. 
16 Hagberg JM, Montain SJ, Martin WH 3rd. Blood pressure and hemodynamic responses after exercise in older hypertensives. J Appl Physiol. 1987;63 (1):270-6.

17 Hauser AM, Dressendorfer RH, Vos M, Hashimoto T, Gordon S, Timmis GC. Symmetric cardiac enlargement in highly trained endurance athletes: a twodimensional echocardiographic study. Am Heart J. 1985;109(5 Pt 1):1038-44.

18 Gava NS, Véras-Silva AS, Negrão CE, Krieger EM. Low-intensity exercise training attenuates cardiac b-adrenergic tone during exercise in spontaneously hypertensive rats. Hypertension. 1995;26(Pt 2):1129-33.

19 Pratley RE, Hagberg JM, Dengel DR, Rogus EM, MullerDC, Goldberg AP. Aerobic exercise training induced reductions in abdominal fat and glucose stimulated insulin responses in mild-aged and older men. J Am Ger Soc. 2000;48(9):2022-33.

20 Brandão Rondon MU, Alves MJ, Braga AM, Teixeira OT, Barreto AC, Krieger EM, Negrão CE. Postexercise blood pressure reduction in elderly hypertensive patients. J Am Coll Cardiol. 2002;39(4):676-82.

21 Lamas GA, Lee KL, Sweeney MO, Silverman R, Leon A, Yee R, Marinchak RA, Flaker G, Schron E, Orav EJ, Hellkamp AS, Greer S, McAnulty J, Ellenbogen K, Ehlert F, Freedman RA, Estes NA 3rd, Greenspon A, Goldman L; Mode Selection Trial in Sinus-Node Dysfunction. Ventricular pacing or dual-chamber pacing for sinus-node dysfunction. N Engl J Med. 2002 Jun 13;346(24):1854-62.

22 Neder AJ, Nery LE. Teste de exercício cardiopulmonar. J Pneumol. 2002;28(Supl 3):s166-s206.

23 Szlachac J, Massie DM, Kramer BL, Topic N, Tabau J. Correlates and prognostic implication of exercise capacity in chronic congestive heart failure. Am J Cardiol. 1985;55(8):1037-42.

24 De Frank I, Katch VL, Mcardle WD. Fisiologia do exercício - nutrição, energia e desempenho humano. $7^{\mathrm{a}}$ ed. Rio de Janeiro: Guanabara Koogan; 2011. 
25 Farinatti TV. Apresentação de uma versão em Português do Compêndio de Atividades Físicas: uma contribuição aos pesquisadores e profissionais em Fisiologia do Exercício. Rev Bras Fisiol Exerc. 2003;2:178-208.

26 Weber KT, Janicki JS. Cardiopulmonary exercise testing: physiologic principles and clinical applications. Philadelphia: WB Saunders; 1986.

27 Guazzi M, Reina G, Tumminello G, Guazzi MD. Improvement of alveolarcapillary membrane diffusing capacity with exercise training in chronic heart failure. J Appl Physiol. 2004;97(5):1866-73.

28 Powers SK, Howley.T. Fisiologia do exercício: teoria aplicada ao condicionamento físico e ao desempenho. $3^{\mathrm{a}}$ ed. São Paulo: Manole; 2000.

29 Yazbek-Jr P, Carvalho RT, Sabbag LMS, Battistella LT. Ergoespirometria. Teste de esforço cardiopulmonar, metodologia e interpretação. Arq Bras Cardiol. 1998;71(5):719-24.

30 Pate RR, Pratt M, Blair SN, Haskell WL, Macera CA, Bouchard C, et al. Physical activity and public health: a recommendation from the Centers for Disease Control and Prevention and the American College of Sports Medicine. JAMA. 1995; 273(5):402-7.

31 Mezzani A, Hamm LF, Jones AM, McBride PE, Moholdt T, Stone JA, Urhausen A, Williams MA; European Association for Cardiovascular Prevention and Rehabilitation; American Association of Cardiovascular and Pulmonary Rehabilitation; Canadian Association of Cardiac Rehabilitation. Aerobic exercise intensity assessment and prescription in cardiac rehabilitation: a joint position statement of the European Association for Cardiovascular Prevention and Rehabilitation, the American Association of Cardiovascular and Pulmonary Rehabilitation and the Canadian Association of Cardiac Rehabilitation. Eur J Prev Cardiol. 2013;20(3):442-67. 
32 Alves GB, Roveda F, Watanabe E, et al. Reabilitação cardiovascular e condicionamento físico. In: Negrão CE; Barreto ACP (eds). Cardiologia do exercício: do atleta ao cardiopata. $2^{\mathrm{a}}$ ed. São Paulo: Manole; 2006. p.261-71.

33 Pollock KM. Exercise in treating depression: broadening the psychotherapist's role. J Clin Psychol. 2001;57:1289-300.

34 Vuori IM. Dose-response of physical activity and low back pain, osteoarthritis, and osteoporosis. Med Sci Sports Exerc. 2001;33(6 suppl):S551-S86.

35 Laterza MC, Matos LDNJ, Trombetta IC, Braga AM, Roveda F, Alves MJ, Krieger EM, Negrão CE, Rondon MU. Exercise training restores baroreflex sensitivity in never-treated hypertensive patients. Hypertension. 2007;49(6):1298306.

36 Sociedade Brasileira de Hipertensão. IV Diretrizes Brasileiras de Hipertensão Arterial - 2002. Capítulo 9. Disponível em: http://www.sbn.org.br. Acesso em: 15 set.2005.

37 Slattery ML, Potter JD. Physical activity and colon cancer: confounding or interaction? Med Sci Sports Exerc. 2002;34(6):913-9.

38 Stratton JR, Levy WC, Cerqueira MD, Schwartz RS, Abrass IB. Cardiovascular responses to exercise. Effects of aging and exercise training in healthy men. Circulation 1994; 89(4):1648-55.

39 Pachón MJC, Mosquéra JAP, Pachón MJC, Vargas RNA, Campos Neto CM, Costa ARB. Aspectos epidemiológicos da estimulação cardíaca no Brasil - $12^{\circ}$ ano do RBM - Registro Brasileiro de Marcapassos, Desfibriladores e Ressincronizadores Cardíacos. Relampa. 2008; 21(1):5-12. 
40 Ciconelli R.M; Ferraz MB, Santos W, Meinão I, Quaresma MR. Tradução para a língua portuguesa e validação do questionário genérico de avaliação de qualidade de vida SF-36 (Brasil SF-36). Rev Bras Reumat. 1999;39(03):143-150.

41 Oliveira BG, Melendez JGV, Ciconelli RM, Rincón LG, Torres AA, de Souza LA, Ribeiro AL. Versão em português, adaptação transcultural e validação de questionário para avaliação da qualidade de vida para pacientes portadores de marcapasso: AQUAREL. Arq Bras Cardiol. 2006; 87(2):75-83.

42 Sharp CT, Busse EF, Burgess JJ, Haennel RG. Exercise prescription for patients with pacemaker. J Cardiopulm Rehabil. 1998;18(6):421-31.

43 Cunha TMB, Cota RMA, Souza BK, Oliveira BG, Ribeiro ALP, Sousa LAP. Correlação entre classe funcional e qualidade de vida em usuários de marcapasso cardíaco. Rev Bras Fisioter. 2007;5:341-45.

44 Lamas GA, Orav EJ, Stambler BS, Ellenbogen KA, Sgarbossa EB, Huang SK, et al. Quality of life and clinical outcomes in elderly patients treated with ventricular pacing as compared with dual-chamber pacing. Pacemaker Selection in the Elderly Investigators. N Engl J Med. 1998;338(16):1097-104.

45 Gomes TB, Gomes LS, Antônio IHF, Barroso TL, Cavalcante AMRZ, Stival MM, Lima LR. Avaliação da qualidade de vida pós-implante de marcapasso cardíaco artificial. Revista Eletrônica de Enfermagem, Goiânia, 2011;13(4):735-42.

46 van Eck JW Martijn1, van Hemel NM, van den Bos A, Taks W, Grobbee DE, Moons KG. Predictors of improved quality of life 1 year after pacemaker implantation. Am Heart J. 2008;156:491-7. 
Guazzi M, Adams V, Conraads V, Halle M, Mezzani A, Vanhees L, Arena R, Fletcher GF, Forman DE, Kitzman DW, Lavie CJ, Myers J; European Association for Cardiovascular Prevention \& Rehabilitation; American Heart Association. EACPR/AHA Scientific Statement Clinical recommendations for cardiopulmonary exercise testing data assessment in specific patient populations. Circulation. 2012;126(18):2261-74.

48 Mancini DM, Eisen H, Kussmaul W, Mull R, Edmunds LH Jr, Wilson JR. Value of peak exercise oxygen consumption for optimal timing of cardiac transplantation in ambulatory patients with heart failure. Circulation. 1991;83:77886.

49 Lemke B, Dryander SV, Jäger D, Machraoui A, MacCarter D, Barmeyer J. Aerobic capacity in rate modulated pacing. Pacing Clin Electrophysiol. 1992;15(11 Pt 2):1914-8.

50 Borg GA. Psychophysical bases of perceived exertion. Med Sci Sport Exerc. 1982; 14(5):377-81.

51 Bassett Jr DR, Howley ET. Limiting factors for maximum oxygen uptake and determinants of endurance performance. Med Sci Sports Exerc. 2000;32(1):70-84.

52 Nunes N, Roberto K, Amaral SL, Proença JE, Braga A, Negrão CE, Alves MJNN, Forjaz CLM. Efeito do treinamento físico, baseado em avaliação ergoespirométrica, na capacidade aeróbica de atletas de voleibol. Rev Bras Cienc Esporte, Campinas, 2008;21:11-15.

53 Zeitler EP, Piccini JJ, Hellkamp AS, Whellan DJ, Jackson KP, Ellis SJ, Kraus WE, Keteyian SJ, Kitzman DW, Ewald GA, Fleg JL, Piña IL, O’Connor CM; HFACTION Investigators. Exercise training and pacing status in patients with heart failure: results from HF-ACTION. J Card Fail. 2015;21(1):60-7. 
54 Udo EO, van Hemel NM, Zuithoff NP, Nijboer H, Taks W, Doevendans PA, Moons KG. Long term quality-of-life in patients with bradycardia pacemaker implantation. Int J Cardiol. 2013;168(3):2159-63.

55 Martinelli Filho M, Siqueira SF, Costa R, Greco OT, Moreira LF, D’Avila A, Heist EK. Conventional versus biventricular pacing in heart failure and bradyarrhythmia: The COMBAT Study. J Card Fail. 2010;16(4):293-300.

56 Belardinelli R, Capestro F, Misiani A, Scipione P, Georgiou D. Moderate exercise training improves functional capacity, quality of life, and endotheliumdependent vasodilation in chronic heart failure patients with implantable cardioverter defibrillators and cardiac resynchronization therapy. Eur J Cardiovasc Prev Rehabil. 2006;13(5):818-25.

57 Arena R, Williams M, Forman DE, Cahalin LP, Coke L, Myers J, Hamm L, Kris-Etherton P, Humphrey R, Bittner V, Lavie CJ, American Heart Association Exercise, Cardiac Rehabilitation and Prevention Committee of the Council on Clinical Cardiology, Council on Epidemiology and Prevention, and Council on Nutrition, Physical Activity and Metabolism. Increasing referral and participation rates to outpatient cardiac rehabilitation: The valuable role of healthcare professionals in the inpatient and home health settings. A science advisory from the American Heart Association. Circulation. 2012;125(10):1321-9. 